\title{
Effects of surface quasi-geostrophic turbulence on phytoplankton competition and coexistence
}

\author{
by Coralie Perruche ${ }^{1}$, Pascal Rivière ${ }^{1,2}$, Guillaume Lapeyre ${ }^{3}$, \\ Xavier Carton ${ }^{4}$ and Philippe Pondaven ${ }^{1}$
}

\begin{abstract}
This paper aims at studying numerically the competition between two mutually exclusive phytoplankton species in a fully-turbulent field consisting of interacting mesoscale and submesoscale structures. A simple NPPZD ecosystem model is embedded in a Surface Quasi-Geostrophic model which is able to reproduce frontogenesis and the associated nutrient vertical pump. The two simulated phytoplankton species differ by their size and their affinity for nutrients. In this study, we rationalize the role played by eddies and filaments in the distribution of the two phytoplankton species. We show that the SQG dynamics are responsible for the coexistence of the two phytoplankton species on a single limiting resource at statistical steady state. In addition, we show that as a result of strong vertical injections, filaments contain $64 \%$ of the phytoplankton biomass. The two phytoplankton species coexist in filaments but the large phytoplankton is predominant. By contrast, this latter is completely excluded from eddy cores where only the small phytoplankton develops. Since eddies are coherent structures (unlike filaments) and since their edges are almost impermeable to horizontal transport, the large phytoplankton can barely enter eddies. Therefore, eddies are ecological niches which shelter the small phytoplankton. Finally we show that interactions between eddies such as eddy merger can favor the survival of phytoplankton species within eddies on long time scales in the ocean.
\end{abstract}

\section{Introduction}

The high diversity of phytoplankton species observed in the global ocean has been the subject of questioning among scientists for a few decades. Large numbers of species stably coexist in limited regions of the ocean. However plankton species live on a very limited number of resources, primarily solar energy and nutrients, and according to the competitive exclusion principle (Hardin, 1960) only a few number of species (equal to the number of limiting resources) should survive. Thus the high phytoplankton diversity observed in reality appears contradictory with the competitive exclusion principle. This was defined as the 'paradox of the plankton' by Hutchinson (1961).

1. Laboratoire des Sciences de l'Environnement Marin, IUEM, CNRS-UBO-IRD, Place Nicolas Copernic, 29280 Plouzané, France.

2. Corresponding author.email: pascal.riviere@univ-brest.fr

3. Laboratoire de Météorologie Dynamique/IPSL, CNRS/ENS, Paris, France.

4. Laboratoire de Physique des Océans, Brest, France. 
Three main solutions to the 'paradox of the plankton' have been put forward (Roy and Chattopadhyay, 2007). Firstly, the influence of external forcings on the ecosystem has been explored. In this case, a fluctuating environment causes the ecosystem to be always out of equilibrium and thus can favor one species at one time, and another species at another. This external forcing can be either purely temporal, such as meteorological forcing, or spatiotemporal, such as ocean dynamics. Secondly, the cause of phytoplankton coexistence can also be found inside the ecosystem itself. Huisman and Weissing (1999) and Huisman et al. (2006) showed that an ecosystem can display self-sustained oscillations and even chaos that allow the coexistence of many phytoplankton species. Lastly, predator-prey interactions are another explanation. Predators, switching from one prey to another, can control the more competitive species, leaving room for the others.

The ocean dynamics and, in particular, mesoscale and associated submesoscale dynamics, have a tremendous effect on biological distribution and production. The ocean is filled all year round by interacting mesoscale eddies. Ubiquitous eddies can be seen in altimeter data (LeTraon and Morrow, 2001) or in the surface chlorophyll distribution via color satellite images (Williams and Follows, 2003). The ocean can, therefore, be represented at first order as a statistically stationary turbulent flow with mesoscale and submesoscale structures permanently forcing planktonic ecosystems. The major results concerning the effects of mesoscale and submesoscale dynamics, and in particular the vertical pump of nutrients, have been obtained during the last decade with numerical process studies (see Klein and Lapeyre, 2009, for a review). Stirring processes were shown to be responsible for the phytoplankton patchiness (Abraham, 1998). At the mesoscale, eddies were shown to account for 20 to $30 \%$ of vertical tracer injections (McGillicuddy et al., 2003). Recently it was proven that submesoscale structures were even stronger upwelling regions than eddies. They are, therefore, key potential sources of nutrients to surface layers. Lévy et al. (2001) showed a doubling of the primary production when submesoscale processes were taken into account, particularly on eddy edges. Martin et al. (2002) compared the effect of largeversus small-scale upwelling spots in a fully developped mesoscale turbulent field. They showed that primary production almost doubled when vertical pumps of nutrients were at the submesoscale for the same total rate of upwelling. Finally, Lapeyre and Klein (2006b) extended these results using a very fine-scale (Surface Quasi-Geostrophic) model representing strongly interacting eddies and diagnosed that almost $50 \%$ of the vertical nutrient fluxes occurred in elongated filaments, well outside eddies, resulting from frontogenesis mechanisms. They also pointed out the importance of intermittent but very strong vertical nutrient fluxes into filamentary structures induced by eddy-eddy interactions during merging processes.

The strong impact of mesoscale and submesoscale motions and especially vertical velocities on phytoplankton production is partly explained by the inverse distribution of nutrients and light in the vertical dimension. Vertical velocities induce nutrient injections in the euphotic layer. As phytoplankton species have different affinities for light and nutrients, mesoscale and submesoscale dynamics are also expected to have a strong influence on the 
competition between phytoplankton species and on the competitive exclusion of some of them. Numerous studies based on in situ observations actually showed different species associations outside, at the periphery and inside eddies (Jeffrey and Hallegraeff, 1980; Vidussi et al., 2001; Sweeney et al., 2003; Vaillancourt et al., 2003) or at a mesoscale front and away from it (Claustre et al., 1994). Eddies may provide shelter for phytoplankton species. They are structures with long life spans in which some phytoplankton species can be isolated from exterior conditions (McGillicuddy et al., 1995). All these studies based on in situ data are very difficult to interpret because they result from the cumulative effects of fluctuating weather, ocean dynamics, etc. This is particularly true of the mesoscale and submesoscale processes for which the sampling has not yet been sufficient to resolve the biological spatio-temporal variability. Numerical modeling offers an alternative to disentangle the effects of the different physical mechanisms which constrain phytoplankton distribution.

In this context we address the general question of the influence of mesoscale and submesoscale dynamics on the competition between phytoplankton species via numerical modeling. Bracco et al. (2000) and Pasquero et al. (2004) tackled this question with two phytoplankton species in competition in a fully turbulent mesoscale field at statistical steady state. They used a quasi-geostrophic model to represent the physical ocean dynamics. Concerning the ecosystem, one phytoplankton was more competitive than the other whatever the external conditions of nutrient concentration. Pasquero et al. (2004) added vertical nutrient injections prescribed through a parameterization using the deformation field (Okubo-Weiss criterion). Both simulations lead to the disappearance of the less competitive species but this process was delayed in such a highly turbulent system. Eddies had a shielding effect on the weakest phytoplankton species which was trapped and sheltered inside vortices. Further studies were undertaken with Primitive Equation (PE) models. Martin et al. (2001), Lima et al. (2002a) and Rivière and Pondaven (2006) studied the response of an ecosystem with two phytoplankton species to a baroclinically unstable zonal jet. These three studies used ecosystem models of different complexity and revealed that competition between phytoplankton species was strongly constrained by 3D dynamics. However they gave very different results on which species (large or small) dominates the other in the turbulent structures of the front. Primitive equation models take into account simultaneously the effects of light gradient, nutrient injections by vertical velocities and dynamics of the mixed layer. Because of the highly non-linear coupling of these mechanisms, the studies of Martin et al. (2001), Lima et al. (2002a) and Rivière and Pondaven (2006) eventually did not give a rationalization of the impact of mesoscale and submesoscale dynamics on the phytoplankton competition outcome.

All these results on competition between phytoplankton species motivate the two following questions: (1) Is coexistence between two phytoplankton species possible on one limiting resource in a fully-turbulent field involving mesoscale and submesoscale processes at statistical steady state? (2) Which dynamical processes govern phytoplankton competition in the different dynamical structures such as eddies and filaments? 
To explore these issues, we adopt a process study approach, using an SQG (Surface Quasi-Geostrophic) model (Lapeyre and Klein, 2006a) which is able to properly represent mesoscale and submesoscale processes involving horizontal stirring and coherent vertical velocities associated with frontogenesis (Klein and Lapeyre, 2009). This model was first proposed by Lesieur and Sadourny (1981) to explain phytoplankton spectra. This differs from studies based on QG equations which do not properly reproduce frontogenesis and the induced strong vertical velocities (Bracco et al., 2000; Pasquero et al., 2004). In addition, we use an NPPZD ecosystem model whose intrinsic dynamics were thoroughly studied (Perruche et al., 2010). Unlike the studies of Martin et al. (2001), Lima et al. (2002a) and Rivière and Pondaven (2006) who used a more realistic ocean dynamics, our purpose is to focus on the effect of one precise mechanism on phytoplankton competition: the threedimensional dynamics of frontogenesis and the induced nutrient injections. In the following section, we will describe both the SQG model, the ecosystem model and the numerical settings. Then we will examine the distribution of two competing phytoplankton species in a fully turbulent field with interacting eddies and rationalize the key-processes responsible for this distribution. Last, we will sum up the main conclusions and show to what extent this study improves our knowledge of phytoplankton patchiness in terms of diversity.

\section{Model description}

\section{a. Surface Quasi-Geostrophic dynamics}

The Surface Quasi-Geostrophic (SQG) model is a special class of quasi-geostrophic flows and describes a surface flow in geostrophic balance, with a small Rossby number over a stably stratified fluid. The density stratification is assumed uniform on average; the density thus takes the form $\rho=\rho_{0}+\bar{\rho}(z)+\rho^{\prime}(x, y, z, t)$. SQG dynamics assume a Lagrangian advection of the surface density by the geostrophic flow. Here, we only consider the surface density anomaly $\rho_{s}=\left.\rho^{\prime}\right|_{z=0}$. The two-dimensional SQG system takes the form (Held et al., 1995):

$$
\begin{gathered}
\frac{d \rho_{s}}{d t}=0 \\
-\left.\frac{f_{0}}{g} \rho_{0} \partial_{z} \psi\right|_{z=0}=\rho_{s}
\end{gathered}
$$

where $d / d t=\partial_{t}()+\mathbf{u} \cdot \nabla(), \mathbf{u}=(u, v)$ are the surface geostrophic velocities, $\psi$ is the streamfunction, $f_{0}$ the Coriolis parameter and $N$, the Brunt-Vaisala frequency. In the following, we consider the case of the northern hemisphere $\left(f_{0}>0\right)$. The streamfunction $\psi$ is related to the geostrophic velocities via $\mathbf{u}=(u, v)=\left(-\partial_{y} \psi, \partial_{x} \psi\right)$. The flow is extended vertically by assuming a zero potential vorticity $Q$ in the interior $(z<0)$.

$$
Q=\nabla^{2} \psi+\partial_{z}\left(\frac{f_{0}^{2}}{N^{2}} \partial_{z} \psi\right)=0, z<0
$$


In this system, when $N^{2}=-\frac{g}{\rho_{0}} \frac{d \bar{\rho}}{d z}$ is a constant, the solution to Eqs. 2 and 3 is $\psi(x, y, z, t)=\hat{\psi}(k, l, t) e^{i(k x+l y)+m z}$ and $\rho_{s}(x, y, t)=\hat{\rho_{s}}(k, l, t) e^{i(k x+l y)}$ for a monochromatic wave with $m=\frac{N}{f_{0}}|\mathbf{k}|$ and $|\mathbf{k}|=\sqrt{k^{2}+l^{2}}$. $\psi$ decreases exponentially toward zero as $z \rightarrow-\infty$. The general solution is obtained by decomposition of the surface density in the spectral space where $\hat{\rho_{s}}(k, l, t)$ is the horizontal Fourier transform of $\rho_{s}(x, y, t)$. Using the hydrostatic balance (Eq. 2) leads to:

$$
\begin{aligned}
& \psi=-\frac{g}{\rho_{0} N} \sum_{\mathbf{k}} \frac{\hat{\rho_{s}}(k, l, t)}{|\mathbf{k}|} \exp \left[i(k x+l y)+\frac{N}{f_{0}}|\mathbf{k}| z\right] \\
& \rho^{\prime}=\sum_{\mathbf{k}} \hat{\rho_{s}}(k, l, t) \exp \left[i(k x+l y)+\frac{N}{f_{0}}|\mathbf{k}| z\right]
\end{aligned}
$$

The ageostrophic vertical velocities are diagnosed from the equation of mass conservation:

$$
w=\frac{g}{\rho_{0} N^{2}}\left(\partial_{t} \rho^{\prime}+\mathbf{u} \cdot \nabla \rho^{\prime}\right)
$$

As for two-dimensional turbulence, the unforced SQG system has two invariants. The first one $\zeta$ is obtained by multiplying Eq. 1 (surface density conservation) by $\rho_{s}$ and integrating it over the surface of the domain:

$$
\zeta=\frac{1}{2}\left(\frac{g}{N \rho_{0}}\right)^{2} \iint \rho_{s}^{2} d x d y
$$

$\zeta$ represents the surface potential energy. The second one $\varepsilon$ is obtained by integrating the product $\psi Q$ over the three-dimensional domain:

$$
\varepsilon=-\frac{1}{2} \frac{g f_{0}}{N^{2} \rho_{0}} \iint \psi \rho_{s} d x d y
$$

$\varepsilon$ represents the three-dimensional total energy. With similar arguments as in twodimensional turbulence (triad interactions), it can be shown that the two invariants imply a dual cascade: surface potential energy $\zeta$ is transferred toward small scales (direct cascade) whereas total energy $\varepsilon$ is transferred toward large scale (inverse cascade) as discussed by Blumen (1978) and Capet et al. (2008).

The SQG model was chosen because it accurately reproduces the $O(50-100 \mathrm{~km})$ mesoscale processes of the first 500 meters of the water column (Lapeyre and Klein, 2006a; Klein et al., 2008), and the $O(10 \mathrm{~km})$ submesoscale processes of the first 100 meters (IsernFontanet et al., 2008; Klein et al., 2009, their Fig. 2). Small scale horizontal motions in SQG are more energetic than in classical QG dynamics, even if it does not create the cyclone/anticyclone asymmetry of the full primitive equation. Because surface density is horizontally strained by the eddies, small-scale fronts are formed with high relative vorticity. This mechanism is related to frontogenesis as described by Hoskins (1982). The filaments 
that develop are transient dynamical structures while the eddies that stretch them are coherent structures associated with a long life span. The velocity field of vortex-dominated flows contains hyperbolic points characterized at the same time by contraction along a compression axis and by stretching along an extension axis. A patch of tracer initialized near a hyperbolic point, simultaneously streches in one direction and contracts in another so that it results in an increasingly thinner filament, eventually aligned along the extension axis, which acts as a transport barrier (see Fig. 3 of Lehahn et al. (2007) for an illustration of the mechanism).

Our numerical SQG simulation is run in a doubly-periodic domain with a spectral resolution of $512 \times 512$ (equivalent to a $3.8 \mathrm{~km}$ resolution). It is adapted from the SQG model of Lapeyre and Klein (2006b) and is run with the same parameter values (as on their Fig. 4). Physical initial conditions are provided by an SQG streamfunction field from the simulation of Lapeyre and Klein (2006b). To properly represent the fully turbulent ocean dynamics, our simulation needs to reach a statistical steady state. For this purpose, one part of the large scale signal has to be filtered to compensate for the total energy inverse cascade. Similarly, one part of the small-scale signal has to be filtered to compensate for the direct cascade of surface potential energy. So, classical low-pass and high-pass filters are used to damp the energy at the smallest and largest scales. The low-pass filter is an exponential cutoff filter of order 6 as described by Smith et al. (2002). The high-pass filter is a hypoviscosity filter (hyperviscosity with negative exponent) of order -4 treated implicitly. Simultaneously, for the two invariants to be conserved on average in time, a forcing term has to be added. Therefore, the density field is forced at large scale with a random field (Smith et al., 2002) with wavenumbers ranging between 5 and 7 and of magnitude $0.018 \mathrm{~kg} \mathrm{~m}^{-3} \mathrm{day}^{-1}$ so that the surface potential energy and the total energy are statistically conserved.

For the sake of simplicity, density is considered to be proportional to temperature. From now on we will speak of temperature instead of density.

\section{b. Ecosystem model}

The ecosystem model is the model used by Perruche et al. (2010); it is a classical NPZD model with 5 biological variables, $N, P_{1}, P_{2}, Z, D$, which are, respectively, nutrients, small phytoplankton, large phytoplankton, zooplankton, and detritus. Each variable is quantified by its equivalent scalar nitrogen concentration $\left(\mathrm{mmol} \mathrm{N} \mathrm{m}^{-3}\right)$. This model is based on the structure of classical NPZD models like those of Fasham et al. (1990), Denman and Pena (1999), Busenberg et al. (1990), Lima et al. (2002b) and Olson and Hood (1994). It is of intermediate complexity with two variables at the autotroph level allowing the study of phytoplankton competition. It is aimed at a pelagic and oligotrophic environment. The ecosystem model is embedded in SQG dynamics as follows: we consider a surface layer of constant depth $h$, which is only represented by one vertical level for the computation of all biological variables. This is similar to assuming that all variables are mean values over depth $h$. The depth of the surface layer is set to $h=100 \mathrm{~m}$. The deep layer is supposed to be 


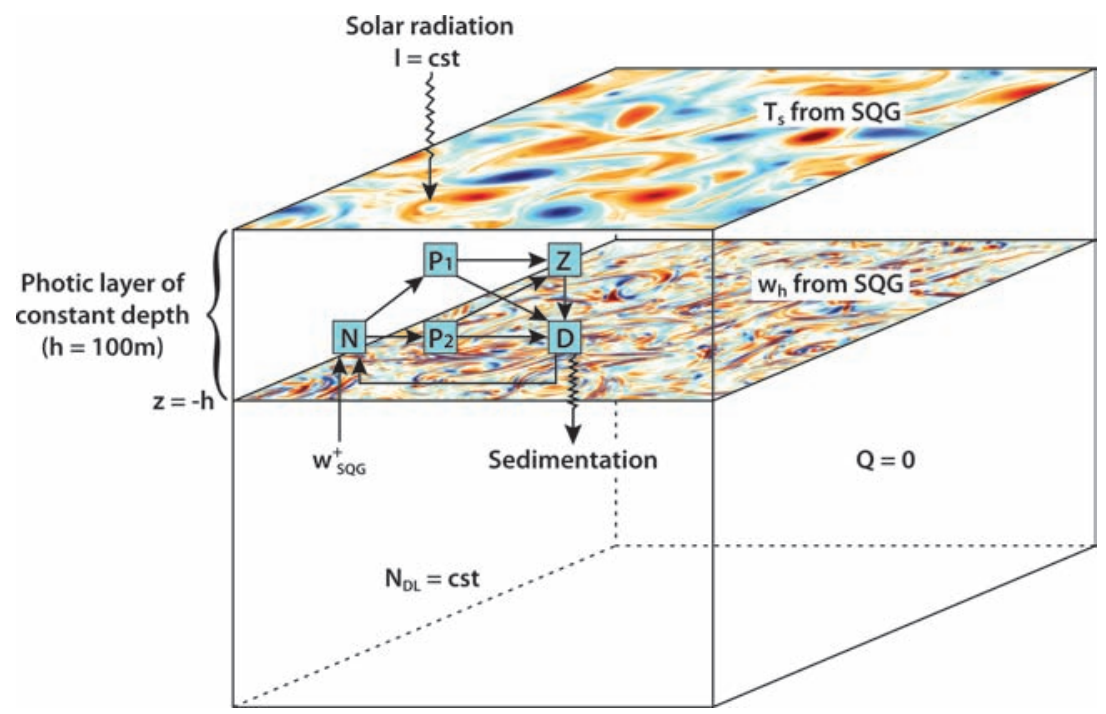

Figure 1. Conceptual scheme representing the NPPZD model advected in the photic layer by the surface geostrophic velocities predicted by SQG dynamics $(\nabla \cdot \mathbf{u}=0)$ that assume that $\mathrm{dT}_{s} / \mathrm{dt}=0$ $\left(\mathrm{T}_{s}\right.$ is proportionnal to $\rho_{s}$ ). Fluxes between the variables of the NPPZD model are represented by arrows. Nutrients are advected from a constant tank $N_{D L}$ to the photic layer via ageostrophic vertical velocities $w^{+}$at $z=-h$ (predicted by SQG dynamics). Detritus are exported from the surface layer via sedimentation. There is a zero potentiel vorticity $Q$ in the ocean interior. Irradiance I is constant.

a dynamically inactive layer for biological variables. This model configuration is summed up on Figure 1.

The non-linear equations of this ecosystem model embedded in SQG dynamics are:

$$
\begin{aligned}
\frac{d N}{d t} & =\tau D-\alpha_{1} \frac{N}{K_{N 1}+N} P_{1}-\alpha_{2} \frac{N}{K_{N 2}+N} P_{2}-\frac{N-N_{D L}}{h} w^{+} \\
\frac{d P_{1}}{d t} & =\left(\alpha_{1} \frac{N}{K_{N 1}+N}-m_{p}\right) P_{1}-g \frac{P_{1}}{K_{Z}+P_{1}+P_{2}} Z \\
\frac{d P_{2}}{d t} & =\left(\alpha_{2} \frac{N}{K_{N 2}+N}-m_{p}\right) P_{2}-g \frac{P_{2}}{K_{Z}+P_{1}+P_{2}} Z \\
\frac{d Z}{d t} & =\left[g \beta \frac{P_{1}+P_{2}}{K_{Z}+P_{1}+P_{2}}-\varepsilon\right] Z \\
\frac{d D}{d t} & =\left[g(1-\beta) \frac{P_{1}+P_{2}}{K_{Z}+P_{1}+P_{2}}\right] Z+m_{p}\left(P_{1}+P_{2}\right)+\varepsilon Z-\tau D-V_{s} D
\end{aligned}
$$

with $w^{+}=\max (w(-h), 0), \alpha_{1}=\mu_{1}\left(1-\exp \left(\frac{-I}{K_{I 1}}\right)\right)$ and $\alpha_{2}=\mu_{2}\left(1-\exp \left(\frac{-I}{K_{I 2}}\right)\right)$ where $I$ is light intensity. $d / d t$ is the $2 \mathrm{D}$ Lagrangian derivative in which only surface geostrophic 
Table 1. Ecosystem model parameters.

\begin{tabular}{llll}
\hline Parameter & Value & \multicolumn{1}{c}{ Unit } & \multicolumn{1}{c}{ Description } \\
\hline Phytoplankton species & & \\
\hline$\mu_{1}$ & 1.9 & day $^{-1}$ & Maximal $P_{1}$ growth rate \\
\hline$\mu_{2}$ & 1.5 & day $^{-1}$ & Maximal $P_{2}$ growth rate \\
\hline$K_{N 1}$ & 0.15 & $\mathrm{mmol} \mathrm{N} \mathrm{m}^{-3}$ & Half saturation constant of $P_{1}$ for nutrient uptake \\
\hline$K_{N 2}$ & 0.6 & $\mathrm{mmol} \mathrm{N} \mathrm{m}^{-3}$ & Half saturation constant of $P_{2}$ for nutrient uptake \\
\hline$K_{I 1}$ & 30 & $\mathrm{~W} \mathrm{~m}^{-2}$ & $P_{1}$ affinity for light \\
\hline$K_{I 2}$ & 5 & $\mathrm{~W} \mathrm{~m}^{-2}$ & $P_{2}$ affinity for light \\
\hline$m_{p}$ & 0.045 & day $^{-1}$ & Phytoplankton mortality rate
\end{tabular}

\section{Zooplankton}

\begin{tabular}{llll}
\hline$g$ & 1.5 & day $^{-1}$ & Maximum ingestion rate \\
\hline$K z$ & 1.4 & $\mathrm{mmol} \mathrm{N} \mathrm{m}^{-3}$ & Half saturation constant for ingestion \\
\hline$\beta$ & 0.2 & & Gross Growth Efficiency for $P_{1}$ and $P_{2}$ \\
\hline$\varepsilon$ & 0.06 & day $^{-1}$ & Mortality rate \\
\hline
\end{tabular}

\section{Detritus}

\begin{tabular}{llll}
\hline$\tau$ & 0.1 & day $^{-1}$ & Specific remineralization rate \\
\hline$V_{s}$ & 0.24 & day $^{-1}$ & Sedimentation speed \\
\hline
\end{tabular}

\section{Nutrients}

\begin{tabular}{|c|c|c|c|}
\hline$N_{D L}$ & 5 & $\mathrm{mmol} \mathrm{N} \mathrm{m}^{-3}$ & Deep ocean nutrient concentration \\
\hline
\end{tabular}

velocities are involved. This implies that there is no convergence or divergence of tracers due to the dynamics, but only nutrient injections (upwelling) through vertical velocities. Definitions and values of the parameters are given in Table 1 . We let the reader refer to Perruche et al. (2010) for a complete discussion of the ecosystem model parameters.

The main motivation of this model choice is related to our process study approach. To address the question of the role of mesoscale and submesoscale dynamics on phytoplankton competition, we need to choose a simple biological set of equations for which exact 0-D intrinsic dynamics (when $u=v=w=V_{s}=0$ ) is known as a dynamical system, and in which phytoplankton competition is possible.

The plankton model here is one of the simplest models of this kind with two phytoplankton and one zooplankton variables. $P_{2}$ is a bloom-forming phytoplankton variable with a higher affinity for light and a lower affinity for nutrient. It will be favored in conditions such as the onset of the growing season in spring (microphytoplankton: "diatom-like" phytoplankton type). On the other hand, $P_{1}$ is a phytoplankton variable with a lower affinity 
for light and a higher affinity for nutrient, competitive in a nutrient-depleted surface layer (picophytoplankton: "small flagellates-like" phytoplankton type). The zooplankton variable has fixed preferences for the two phytoplankton species. Thus, it has a mean control on the two species.

A full description of the biological system equilibria and their stability in the parameter space can be found in Perruche et al. (2010). Here we give only the two main conclusions. First, the coexistence of the two species of phytoplankton is not possible at all in the parameter space in 0-D. The ecosystem reaches different equilibria with either $P_{1}$ or $P_{2}$. Second, the ecosystem is particularly sensitive to the variations in light and total nitrogen (see their Fig. 3). Total nitrogen, that will be called $C_{0}$ in the following, is the sum of the five biological variables: $C_{0}=N+P_{1}+P_{2}+Z+D$. In 0 -D, total nitrogen $C_{0}$ is conserved along time, but it is strongly variable in an oceanic basin. Horizontally, nitrogen matter varies due to the combined advection and diffusion processes.

We are aware that this ecosystem model is extremely simple regarding parameterizations of phytoplankton or zooplankton biological processes. However, justification for using such a simple model in our study is determined by the question being explored: how submesoscale dynamics may influence ecosystem structure in the ocean? As pointed out by Franks (2002), it is impossible to diagnose and interpret model results in such a scenario, where a biological model is embedded in a highly turbulent field, without knowing the range of model behaviors (in a mathematical sense). This knowledge of model behavior (stability and equilibria) implies, however, some restrictions on the number of state variables and model parameterizations. Therefore, the biological model used here is admittedly biased toward simplicity, which renders it less realistic and certainly not suitable to describe all kind of situations. The pitfalls of using such models have been discussed by Anderson and Mitra (2010) or Flynn (2003, 2010). A typical example is the use of fixed Monod or Holling formulations to simulate phytoplankton growth or grazing by zooplankton in the context of multiple-resource interactions. A more mechanistic understanding of these biological processes can be embedded in models, which substantially increases the realism of these models (Mitra et al., 2007; Mitra and Flynn, 2005, 2006; Anderson and Mitra, 2010; Flynn, 2003, 2010). These approaches, based on controlled laboratory experiments, are important steps to refine the realism of plankton ecosystem models which aim at addressing (for example) the impact of climate change on marine ecosystems. However, in our present process study, we have to stick to more simple model formulations. Indeed, the model is simple enough to determine analytically the ecosystem behavior in the whole parameter space (Perruche et al., 2010), and give a reasonable picture of the general planktonic community response to realistic seasonal physical forcings in a 1D modeling framework (Perruche, 2009). This knowledge of the model behavior (equilibria and stability) is a prerequisite to investigate the relative influence of physical processes at the submesoscale. We believe that these two modeling approaches (realism vs simplicity) are not mutually exclusive and both help to understand how marine ecosystems may respond to a variable environment. 
The five biological variables of Eqs. 9 to 13 are considered as vertically averaged values over the surface layer which represents a photic layer $(h=100 \mathrm{~m})$. Biological tracers are initialized in the surface layer to uniformly small values $\left(N_{0}=0, P_{10}=0.1, P_{20}=0.1\right.$, $Z_{0}=0.1$ and $D_{0}=0 \mathrm{in} \mathrm{mmol} \mathrm{N} \mathrm{m}^{-3}$ ). The deep layer corresponds to the deep ocean nutrient reservoir. It is supposed to be nutrient abundant with nutrient concentration $N_{D L}$ maintained to a constant value of $5 \mathrm{mmol} \mathrm{N} \mathrm{m}^{-3}$. The other biological variables are set to zero in the deep layer. The interface between surface and deep layers is the nutricline. This nutricline is strong and can be thought to result from a restratification process induced by the ageostrophic motions (see e.g. Klein et al., 2008). In this simplified model we neglect the dynamics of the mixed layer which is supposed to be shallower than the euphotic layer.

A nutrient injection term (last term of Eq. 9) is prescribed at the base of the surface layer as was done by Flierl and Davis (1993). Nutrients are advected upward by ageostrophic vertical velocities at $z=-h$. The hypothesis of a constant pool of nutrients in the deep layer imposes that only the positive values of $w$ have to be considered for nutrients (vertical inputs of nutrients). No downward flux of $P_{1}, P_{2}, Z$ and $D$ is allowed. As a pseudo-spectral model is used, negative values of biological variables can appear due to the Fourier transform. In this case, they are set to zero and the mean over the whole domain is maintained to its previous value so that no artificial source is created. An exponential filter is also used for smallscale dissipation in the tracer equations (Eqs. 9 to 13). As mentioned before, the physical SQG model is brought toward statistical equilibrium. This implies that the magnitude of the nutrient pump is statistically conserved. The sedimentation term on detritus $V_{s} D$ is the only term that allows nitrogen matter to be exported from the surface layer. Therefore, via the sedimentation process, the concentration of nitrogen matter in this layer remains constant on average. For purposes of mass balance, this compensates the nutrient injections into the surface layer. The value of the sedimentation speed $V_{s}$ is indicated in Table 1. It was estimated with the mean value of injection velocities into the surface layer and it is very close to the value chosen by Martin et al. (2002). Remineralization of detritus is supposed to be instantaneous when they enter the bottom layer.

Phytoplankton in the surface layer is submitted to a constant light intensity (set to $I=$ $10 \mathrm{~W} \mathrm{~m}^{-2}$ ) which corresponds to the vertically averaged irradiance absorbed by the $100 \mathrm{~m}$ surface layer. If we consider an absorption coefficient of $0.045 \mathrm{~m}^{-1}$, which is close to the pure water absorption (no self-shading), the mean value $\mathrm{I}=10 \mathrm{~W} \mathrm{~m}^{-2}$ corresponds to a surface irradiance of about $45 \mathrm{~W} \mathrm{~m}^{-2}$. Figure 2 presents the growth rates $\left(\alpha_{i} N /\left(K_{N i}+N\right)\right)$ of the two phytoplankton species when submitted to a light intensity of $10 \mathrm{~W} \mathrm{~m}^{-2}$. It shows that $P_{1}$ has the highest growth rate for low nutrient concentration and inversely for $P_{2}$. We can predict that the most competitive species will be $P_{1}$ for low nutrient injections and $P_{2}$ for high nutrient injections.

This model which is presented in Figure 1 is aimed at studying competition between the two phytoplankton species in terms of segregation or coexistence in the physical space and especially in dynamical structures like eddies and filaments. We chose a very simple configuration with two layers to free ourselves from the vertical gradient of light. Thus, there 


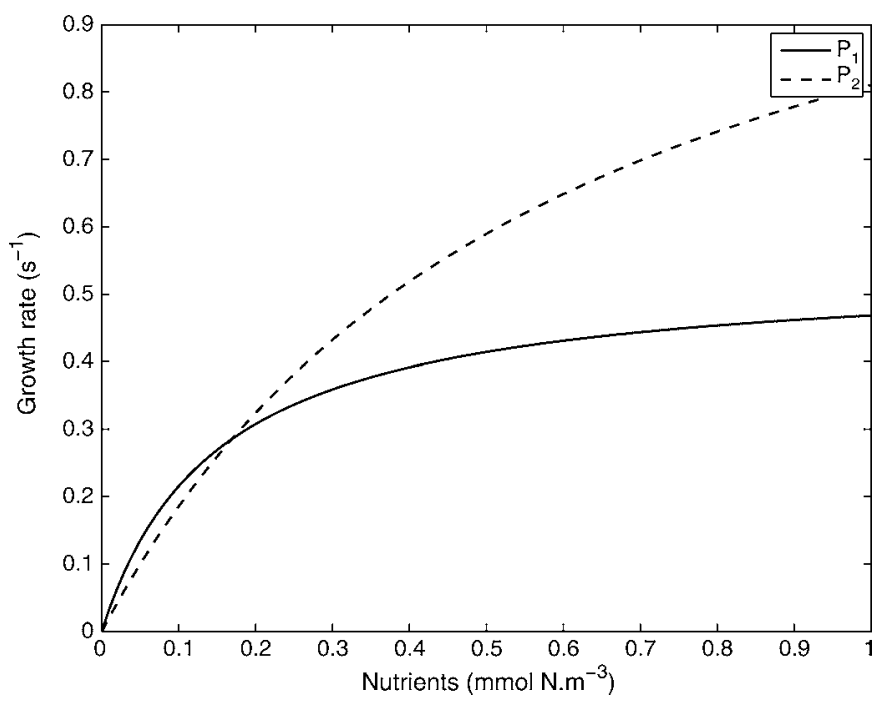

Figure 2. Growth rates $\left(\mathrm{s}^{-1}\right)$ of $P_{1}$ and $P_{2}$ as a function of nutrient concentration $\left(\mathrm{mmol} \mathrm{N} \mathrm{m}^{-3}\right)$.

is only one limiting resource (nutrients) and we can focus on the role of nutrient vertical pump and of horizontal advection on competition between two phytoplankton species.

\section{Results}

\section{a. Physical fields}

We run a 3-year long simulation. We first study the physical properties of this simulation. Figure 3 shows total energy and surface potential energy. After a transient period of 200 days, these quantities are statistically balanced. All the statistics performed hereafter will concern the last two years of this simulation.
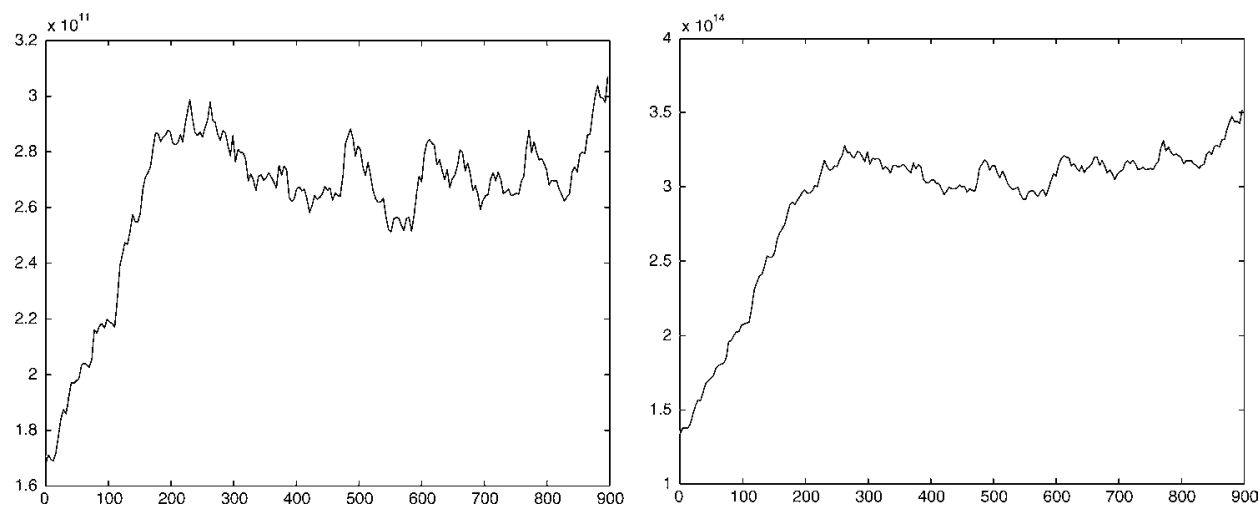

Figure 3. (left) Surface potential energy $\zeta\left(\mathrm{m}^{4} \mathrm{~s}^{-2}\right)$ as a function of time (days); (right) Total energy $\varepsilon\left(\mathrm{m}^{5} \mathrm{~s}^{-2}\right)$ as a function of time 
Figure 4 shows the temperature anomaly, the relative vorticity in the surface layer and the 100-m depth vertical velocity field after 2 years of simulation (day 722). This moment of the simulation was chosen for its representativity of the statistical steady state, both for the physical fields and for the biological ones. The temperature field in the surface layer (Fig. 4a) consists in interacting mesoscale eddies and displays, between them, quite weak small-scale temperature anomalies. In the vorticity field (Fig. 4b) filaments are much thinner. Eddies, in the temperature field, are quite homogeneous whereas in the vorticity field they can be divided in a homogeneous eddy core and in curled filaments at their periphery. Vorticity has the same magnitude in eddies and filaments. The vertical velocity at 100-m depth (Fig. 4c) also involves small scales with thin filaments. The magnitude of vertical velocity is rather weak in eddy cores, it is stronger at the periphery and it is maximum in filaments between eddies. Most eddies (with elliptical shape) are associated with quadrupolar structures in vertical velocity field whereas filaments are associated with dipolar patterns. This is consistent with previous results (Lévy et al., 2001; Lapeyre and Klein, 2006b). Vertical velocity within filaments has a magnitude on order of $10 \mathrm{~m} \mathrm{day}^{-1}$ and can reach up to $40 \mathrm{~m} \mathrm{day}^{-1}$. This order of magnitude corresponds to values diagnosed from a high-resolution survey by Legal et al. (2007) in density-compensated fronts far-off eddies during the POMME experiment. It is expected that these strong vertical velocities outside eddies will have a crucial effect on the vertical nutrient pump (Lapeyre and Klein, 2006b) and therefore on primary production and phytoplankton competition.

From these physical fields, we can see that cyclones and anticyclones are absolutely symmetrical. This is a property of SQG dynamics which impose a geostrophic horizontal flow. To create an asymmetry, we would have to consider an SQG+1 model which allows ageostrophic horizontal velocities (Hakim et al., 2002).

At first glance, a noticeable difference on spatial scales between the temperature field and the two other fields can be noticed. Temperature mainly consists in mesoscale structures whereas vorticity and vertical velocity are much more filamentary. This physical property is due to the ageostrophic circulation which restores the thermal wind balance (Hoskins, 1982). As shown by the classical $\omega$-equation (Hoskins et al., 1978), still valid in SQG theory, ageostrophic vertical velocities are a response to the formation of density gradients and inhibit too strong gradients. They compensate the formation of strong temperature gradients. As a consequence, the temperature field is smoother than the other dynamical variables.

As we have shown in the previous paragraph, the physical fields of Figure 4 are typical of SQG dynamics. The main difference between our simulation and the one performed by Lapeyre and Klein (2006b) is the forcing term and the large-scale dissipation term that we added for the modeled dynamics to reach a statistical steady state. Therefore, our simulation is overall more energetic which results in stronger physical anomalies. The eddy interactions are more intense and induce more filamentary structures (clearly visible in the vorticity field) associated with strong vertical velocities. The spectrum of density variance (rescaled by $g^{2} / N^{2} \rho_{0}^{2}$ ) gives further information on the spatial scales of our SQG simulation 

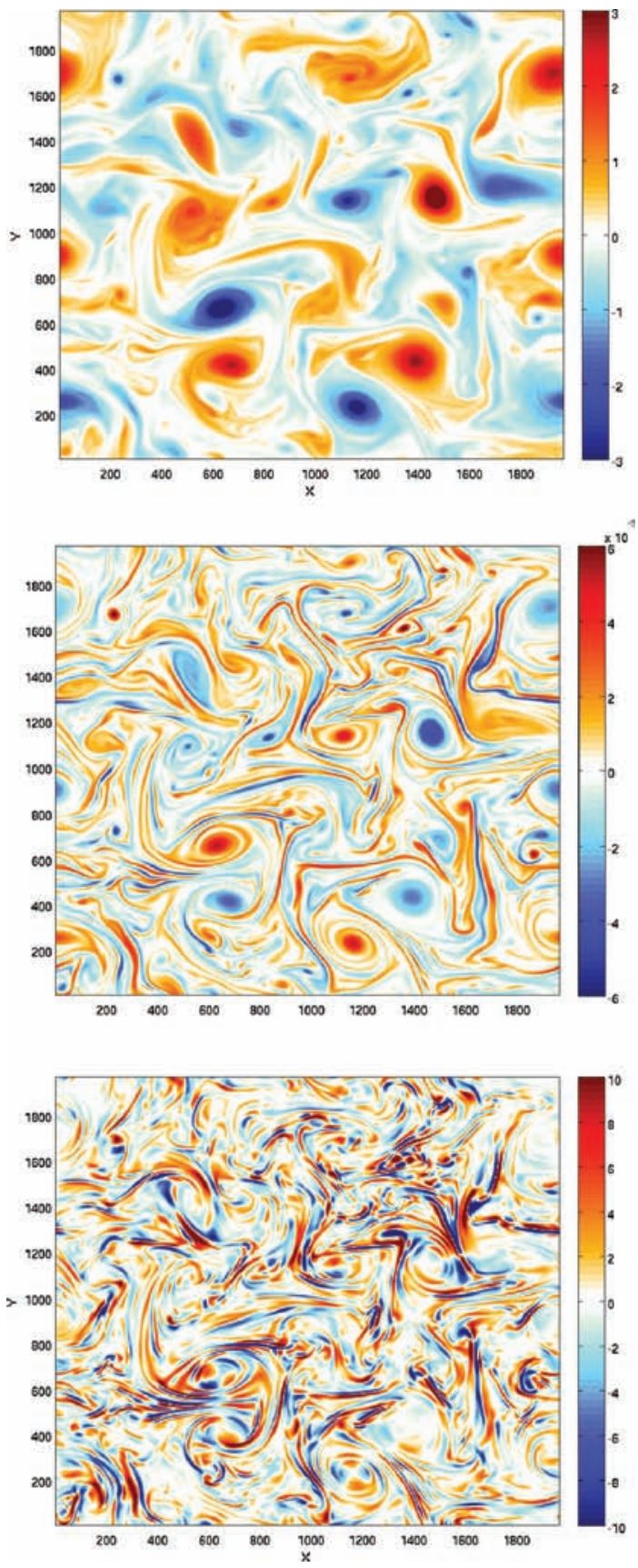

Figure 4. Physical fields at day 722; (top): temperature anomaly (in Celsius degree); (middle): vorticity anomaly $\left(\mathrm{s}^{-1}\right)$; (bottom): vertical velocity anomaly $\left(\mathrm{m} \mathrm{day}^{-1}\right)$. Axes are in $\mathrm{km}$. Northern hemisphere. 


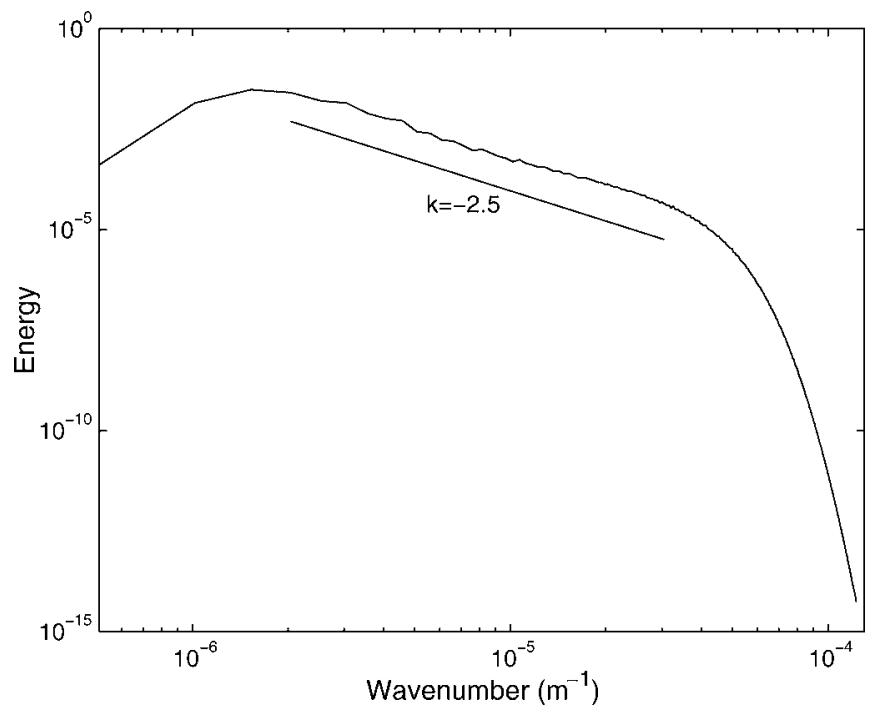

Figure 5. Surface potential energy spectrum averaged over time between day 300 and $900\left(\mathrm{~m}^{2} \mathrm{~s}^{-2}\right)$.

(Fig. 5). Its slope is comparable to the results based on data of Martin and Srokosz (2002) (slope of -2.11 ) and to ' $512 \times 512$ ' numerical simulation of Capet et al. (2008). The energy spectrum slope is steeper than the theoretical $-5 / 3$.

We can examine in detail three interacting eddies in the fully-turbulent field. These three cases are presented on Figure 6, both in vorticity (left) and vertical velocity (right) and illustrate three typical eddy interactions picked out in the reference simulation at three different times. First, Figure $6 \mathrm{a}$ and $6 \mathrm{~b}$ show a cyclonic eddy, 'isolated' from other eddies, and interacting with filaments surrounding it. It moves only slightly and it is distorted by the ambient shear and strain fields, due to the surrounding flow. This influence leads to a clear elliptical shape of the eddy. Its vertical velocity pattern is quadrupolar, as expected from the presence of a mode 2 disturbance (see also Baey and Carton, 2002). In vorticity, this eddy has a spiral-like shape. This shape can be interpreted following Lehahn et al. (2007) who argue that since trajectories and streamlines are different for a time-dependent velocity field, a spiral flow can be induced. Then, Figure $6 \mathrm{c}$ to $6 \mathrm{f}$ show eddy-eddy interactions whose outcome depends on their polarity. On Figure $6 \mathrm{c}$ and $6 \mathrm{~d}$, the two eddies have the same sign. In that case, they mutually attract each other so as they begin to interact and to distort their partner leading to the merger of the two eddies. When they are sufficiently close, a hyperbolic point appears between them. A filament of opposite vorticity separates them (Fig. 6c) until they merge. The corresponding vertical velocity field (Fig. 6d) displays strong vertical velocities at the periphery of eddies and relatively weak velocities in their cores. If two eddies of opposite sign meet (Fig. 6e and 6f), the pairing of the two vortices occurs and they form a propagating dipole of eddies. At the dipole front (bottom of the 
(a)

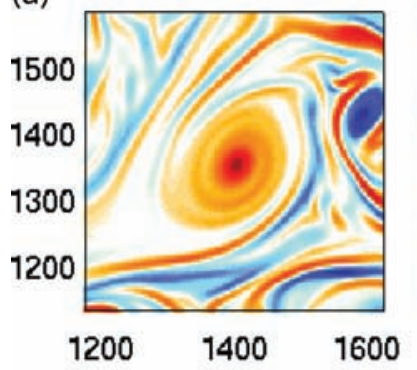

(c)

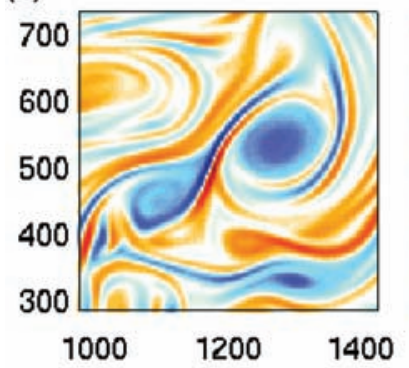

(e)

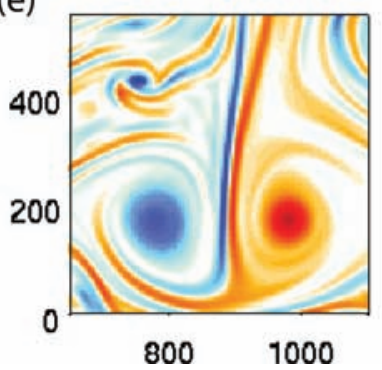

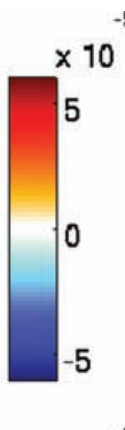
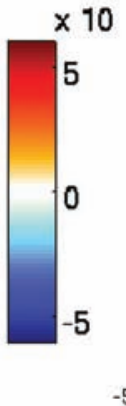

$\times 10$

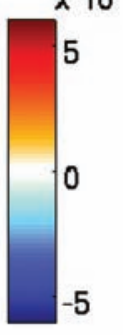

(b)

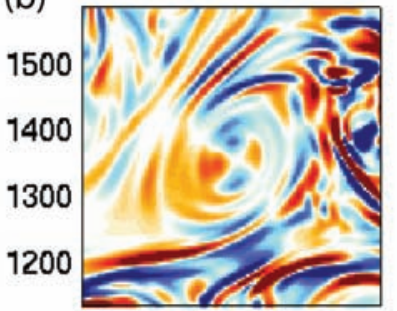

$1200 \quad 1400 \quad 1600$

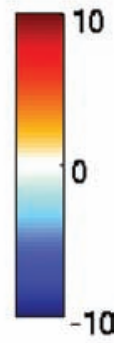

(d)
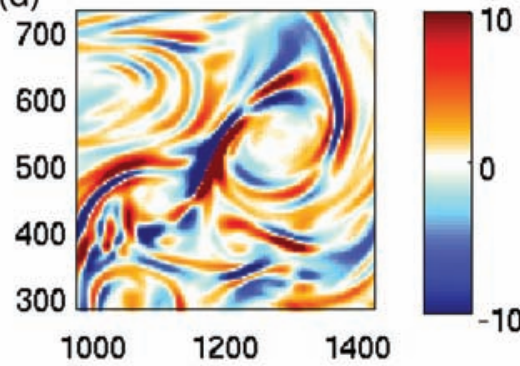

$-10$

(f)

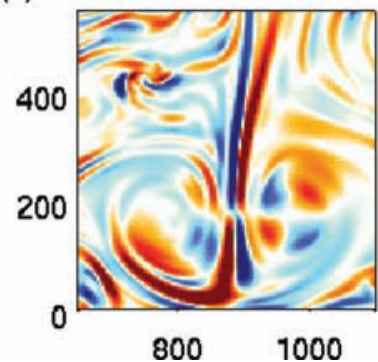

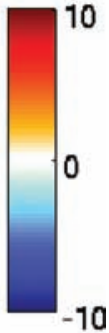

Figure 6. Three zooms at different times of the simulation (not the same as in Fig. 4), illustrating three cases of eddy interaction. (Top) Cyclonic 'Isolated' eddy; (Middle) Like-signed eddies; (Bottom) A dipole of opposite sign; (left) vorticity anomaly $\left(\mathrm{s}^{-1}\right)$; (right) vertical velocity anomaly $\left(\mathrm{m} \mathrm{day}^{-1}\right.$ ). Axes are in $\mathrm{km}$.

snapshots), a few filaments of alternate signs in vorticity form perpendicularly to the dipole route and collide with the structures encountered by the dipole (Fig. 6e). At the dipole tail, there are filaments of opposite sign. Each filament of the pair curls around the eddy of the same sign. This dipole results in two quadrupolar structures in vertical velocity field (Fig. 6f) and in intense vertical injection in filaments at eddy front and tail.

In addition to these interactions between eddies, we also observe eddy-filament interactions which are of two types (not shown). Either eddy and filament have the same polarity 


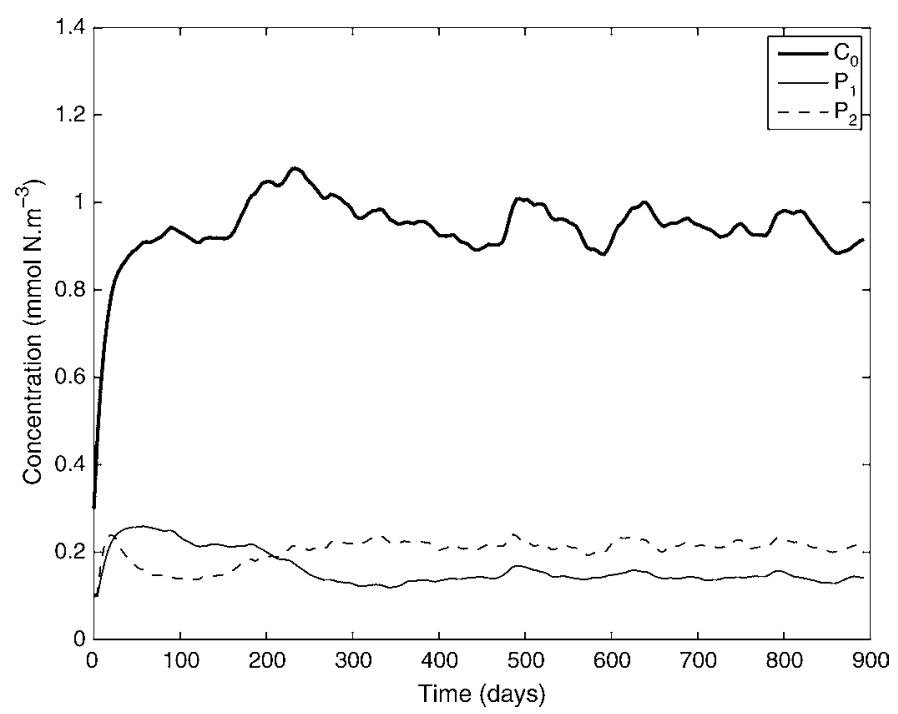

Figure 7. Time series of $C_{0}, P_{1}$ and $P_{2}$ averaged over the whole domain $\left(\mathrm{mmol} \mathrm{N} \mathrm{m}^{-3}\right)$.

and the filament curls around the eddy and can be absorbed, or they are of opposite sign and the filament cannot be absorbed. In the latter case, the filament curls around the eddy and is then dissipated or it forms at a hyperbolic point and stretches until it splits in two parts that move away from each other.

\section{b. Biological fields}

We now examine the outcome of the competition between the two phytoplankton species $P_{1}$ and $P_{2}$ in this fully turbulent eddy field at statistical steady state. Figure 7 shows the mean value of $C_{0}, P_{1}$ and $P_{2}$ over the domain as a function of time. As for the physical fields, biology achieves a statistical equilibrium for all five variables after a 200 day transient period ( $N, Z$ and $D$ not shown). As a consequence, total nitrogen $C_{0}$ is also statistically balanced in the surface layer. This statistical equilibrium is characterized by phytoplankton coexistence when submitted to a fully-turbulent flow (see again Fig. 7). Their averaged concentrations over the spatial domain are of the same order, about $0.14 \mathrm{mmol} \mathrm{N} \mathrm{m}^{-3}$ for $P_{1}$ and $0.21 \mathrm{mmol} \mathrm{N} \mathrm{m}^{-3}$ for $P_{2}$ (the other variables are not shown on the figure but have a similar temporal evolution and the same order, namely $0.14 \mathrm{mmol} \mathrm{N} \mathrm{m}^{-3}$ for $\mathrm{N}, 0.21 \mathrm{mmol} \mathrm{N} \mathrm{m}^{-3}$ for $\mathrm{Z}$ and $0.23 \mathrm{mmol} \mathrm{N} \mathrm{m}^{-3}$ for $\mathrm{D}$ ). It should be recalled that in a motionless ocean, these species $P_{1}$ and $P_{2}$ would not be able to coexist (Perruche et al., 2010). This shows that in this simulation, mesoscale and submesoscale dynamics allow $P_{1}$ and $P_{2}$ to coexist on a long period of time.

Although the two phytoplankton species coexist on average over the whole domain with similar concentrations, they do not have the same spatial distribution as shown on snapshots 

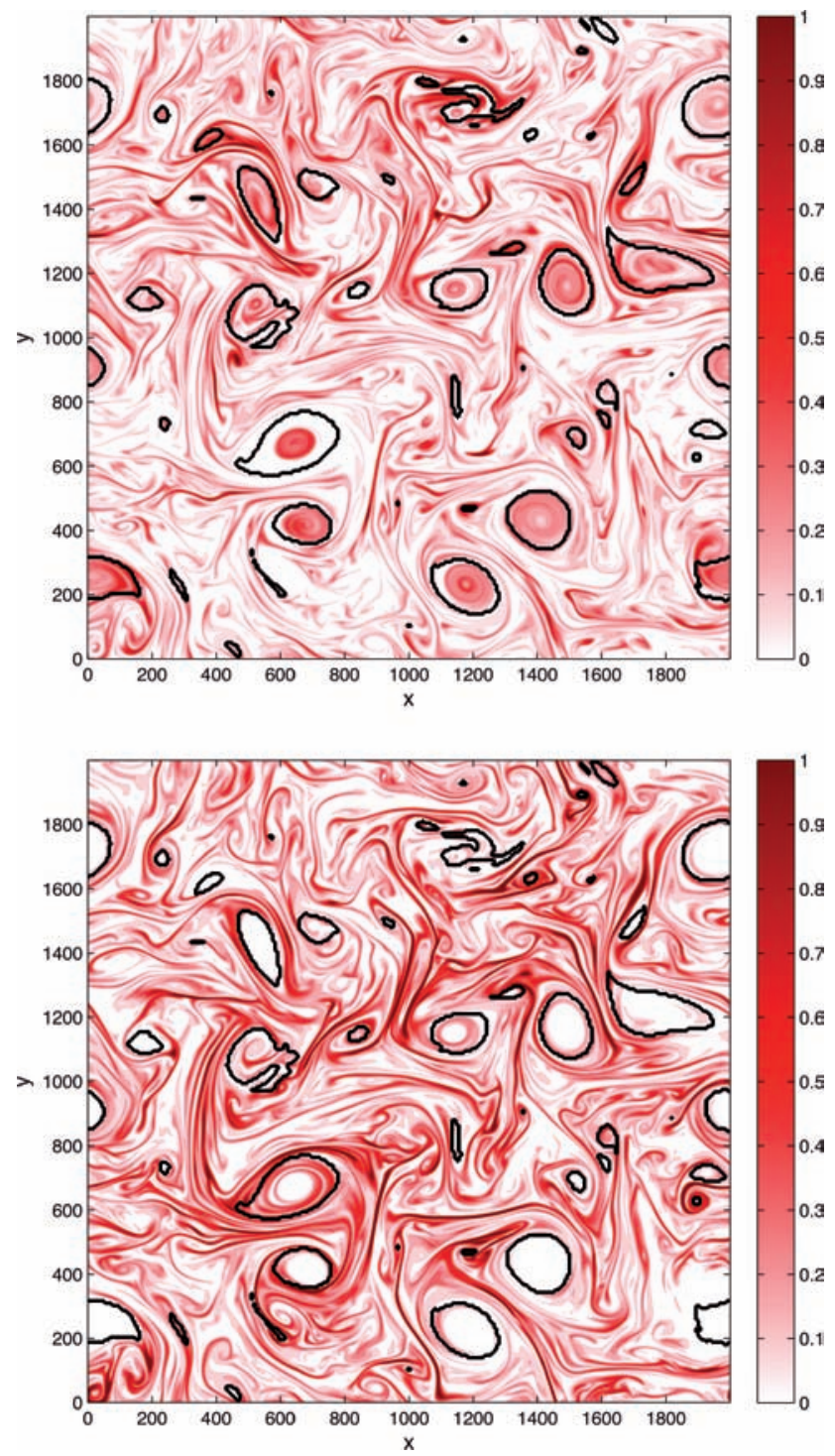

Figure 8. Phytoplankton snapshots after 2 years of simulation (day 722) in $\mathrm{mmol} \mathrm{N} \mathrm{m}^{-3}$ : (top) $P_{1}$; (bottom) $P_{2}$. The time of these snapshots is the same as the one of Figure 4. Superimposed are the contours of eddies as diagnosed by the partition algorithm. Axes are in $\mathrm{km}$.

of Figure 8. Most of the biomass is located in filaments and $P_{2}$ is dominant in these structures. On the other hand, $P_{2}$ is completely excluded from eddy cores where only $P_{1}$ manages to develop. In addition, it appears that $P_{2}$ develops at smaller scales than $P_{1}$. This feature is visible on the normalized power spectral density of the two phytoplankton species (Fig. 9). 


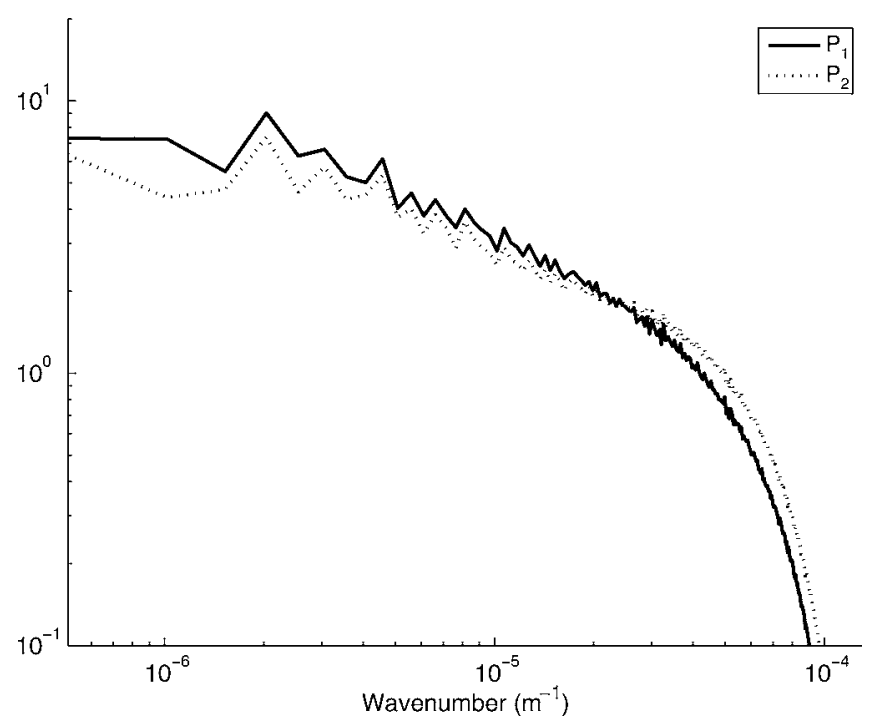

Figure 9. Normalized power spectral density of $P_{1}$ (continuous line) and $P_{2}$ (dotted line) averaged over 600 days (between day 300 and 900).

The spectrum of $P_{1}$ is slightly steeper than that of $P_{2}$. We conclude that $P_{2}$ is therefore stronger than $P_{1}$ at small scales and conversely.

To distinguish the different dynamical structures and to perform calculations over them, an algorithm first separates eddies from filaments via a wavelet decomposition and then separates curved from elongated filaments using a quantification of the curvature (Lapeyre and Klein, 2006b). The choice of this spatial decomposition is motivated by the fact that $P_{1}$ is clearly dominant in eddies, and $P_{2}$ in very stretched filaments, which are completely detached from eddies. This segregation is less clear in the curved filaments around eddies. So this decomposition applies to our observations concerning the distribution of phytoplankton in dynamical structures. One example of the eddy partition is shown on Figure 8 by the black contours. It is important to notice that $P_{1}$ develops preferentially in eddy cores and $P_{2}$ at their periphery. The eddy detection includes both the core and periphery of eddies. This decomposition results in respectively $10 \%, 27 \%$ and $63 \%$ of the domain occupied by eddies, curved and elongated filaments when one averages the decomposition over 600 days (Table 2). The features described in the physical field section are confirmed by the partition of temperature anomaly variance $\left(\theta^{2}\right)$ and vertical velocity anomaly variance $\left(w^{2}\right)$ over these types of structures. $59 \%$ of the temperature anomaly variance compared with only $8 \%$ of vertical velocity anomaly variance is actually located inside eddies which corroborates the fact that temperature consists of mesoscale structures whereas vertical velocity is stronger in filaments (Table 2).

Mean and standard deviation are determined over eddies, elongated and curved filaments on a period of 600 days at steady state. These statistical calculations (Table 3) corroborate 
Table 2. Partition of property $\mathrm{P}$ (given in $\%$ of total) between the different types of structures (eddies, curved and elongated filaments) over a period of 600 days between day 300 and 900 . Properties: surface area $(\mathrm{S})$, temperature anomaly variance $\left(\theta^{2}\right)$, vertical velocity anomaly variance $\left(w^{2}\right)$ and biomass amount in the surface layer.

\begin{tabular}{lcccc}
\hline Property & $\% \mathrm{~S}$ & $\% \theta^{2}$ & $\% w^{2}$ & $\%$ biomass \\
\hline Eddies & 10 & 59 & 8 & 10 \\
\hline Curved filaments & 27 & 15 & 17 & 26 \\
\hline Elongated filaments & 63 & 26 & 75 & 64 \\
\hline
\end{tabular}

preliminary observations. $P_{1}$ is indeed more concentrated in eddies $\left(0.22 \mathrm{mmol} \mathrm{N} \mathrm{m}^{-3}\right.$ to be compared with $0.13 \mathrm{mmol} \mathrm{N} \mathrm{m}{ }^{-3}$ in curved as well as in elongated filaments) and $P_{2}$ is more concentrated in filaments $\left(0.21\right.$ and $0.23 \mathrm{mmol} \mathrm{N} \mathrm{m}^{-3}$ respectively in curved and elongated filaments, to be compared with $0.14 \mathrm{mmol} \mathrm{N} \mathrm{m}^{-3}$ in eddies). These concentrations of $P_{1}$ and $P_{2}$ in the eddies reflect both the dominance of $P_{2}$ at the eddy periphery and the exclusion of $P_{2}$ by $P_{1}$ in eddy core. The concentrations of the two phytoplankton species in eddies are not negligeable and are the consequence of the spatial segregation of phytoplankton species inside eddies (see for instance eddy at $x=600, y=600$ on Fig. 8). The dominance $\left(P_{2}-P_{1}\right) /\left(P_{1}+P_{2}\right)$ is on average -0.25 in eddies, 0.17 in curved filaments and 0.20 in elongated filaments. This confirms the dominance of $P_{1}$ in eddies and of $P_{2}$ in filaments. Furthermore, the spatially averaged standard deviation is more important for $P_{2}$ in filaments than $P_{1}$ (Table 3). This means that $P_{2}$ undergoes wider variations than $P_{1}$ and it supports the fact that the field of $P_{2}$ displays more small scales.

In terms of phytoplankton biomass, eddies contain only $10 \%$ of the total phytoplankton biomass. Curved and elongated filaments, on the other hand contain respectively $26 \%$ and $64 \%$ of total phytoplankton biomass (Table 2). As the area occupied by filaments is larger than the area of eddies, phytoplankton biomass is mainly contained in filaments. We obtain very similar percentages for primary production (not shown). Filaments play a significant role in the biomass and primary production balance as expected by Lapeyre and Klein (2006b). This result is in accordance with the conclusions of Lévy et al. (2001) and Lévy (2003).

Table 3. Mean and standard deviation (Std) of $P_{1}$ and $P_{2}$ concentrations inside eddies, curved and elongated filaments averaged over a period of 600 days (between day 300 and 900).

\begin{tabular}{lcccc}
\hline & $P_{1}$ & & $P_{2}$ & \\
\hline Eddies & Mean & Std & Mean & Std \\
\hline Curved filaments & 0.22 & 0.20 & 0.14 & 0.20 \\
\hline Elongated filaments & 0.13 & 0.13 & 0.21 & 0.22 \\
\hline
\end{tabular}


Our purpose now is to understand which physical mechanisms drive this phytoplankton distribution. Let us recall the intrinsic features of the two phytoplankton species. With an irradiance of $10 \mathrm{~W} \mathrm{~m}^{-2}$, the ecosystem model alone predicts that $P_{1}$ is dominant for low $C_{0}$ (total nitrogen) and $P_{2}$ for high $C_{0}$ (see Fig. 2). Therefore, we expect the growth of $P_{2}$ when strong injections occur and conversely the growth of $P_{1}$ when low injections occur. Lapeyre and Klein (2006b) studied the spatial organization of a passive tracer and proved that a significant amount of tracers (almost 50\%) was found within elongated filaments and that almost $50 \%$ of the vertical injections occurred within or close to them. This result is explained by the large area occupied by elongated filaments and by the strong values of vertical velocities in these structures. Thus, one can expect the development of $P_{2}$ preferentially within elongated filaments. Concerning $P_{1}$, the situation is less clear: eddy colonization by $P_{1}$ may be either due to the horizontal advection of nutrients inside eddies or to the vertical nutrient injections inside eddies.

To better understand this distribution, we run two experiments from day 600 of our reference simulation (at steady state at that time). These simulations have exactly the same properties as the reference one, except that we cut off the nutrient vertical injections within eddy cores in one case, and out of eddy cores in the other. These contours are determined on-line through a temperature criterion (isoline $1.5^{\circ} \mathrm{C}$ ). The goal is to determine why $P_{1}$ is able to survive inside eddies. Snapshots of the reference simulation and of each experiment are presented on Figure 10 with one row for each after 186 days of simulation (from day 600). The maps of $P_{1}$ and $P_{2}$ are presented in the left and right columns, respectively. The main result is that without vertical injection in eddy cores, $P_{1}$ does not develop there anymore. This shows that mainly vertical injections, and not the horizontal stirring of nutrients, allow $P_{1}$ to survive in eddy cores. Figure 11 represents the injections of nutrients of the reference simulation at the same time as snapshots of Figure 10 and shows that injections in eddies are actually limited in comparison with injections in filaments. Since the growth rate of $P_{1}$ is larger than that of $P_{2}$ with limited nutrients (see Fig. 2 obtained from the growth terms of Eqs. 10 and 11), $P_{1}$ is competitive against $P_{2}$ in eddies. In addition, it is almost isolated from $P_{2}$ within eddy cores. Eddies are coherent structures which form 'ecological niches' where $P_{1}$ can develop, sheltered from $P_{2}$. We have ignored in our model the divergent horizontal ageostrophic motions but we may think that the eddy cores remain barriers to transport in light of results of Lévy et al. (2001) for a primitive equation simulation. When vertical injections are set only outside eddies, the two phytoplankton species still coexist over the domain at statistical equilibrium, but $P_{2}$ is more dominant on average $\left(0.13 \mathrm{mmol} \mathrm{N} \mathrm{m}^{-3}\right.$ for $P_{1}$ and $0.22 \mathrm{mmol} \mathrm{N} \mathrm{m}^{-3}$ for $\left.P_{2}\right)$. When nutrient injections are performed inside eddies, $P_{2}$ almost dies whereas $P_{1}$ persists durably within eddies but with very low values of spatially-averaged biomass at statistical steady state $\left(0.02 \mathrm{mmol} \mathrm{N} \mathrm{m}^{-3}\right.$ for $P_{1}$ and $0.002 \mathrm{mmol} \mathrm{N} \mathrm{m}^{-3}$ ). Considering the strong vertical injections within filaments, this analysis reveals that filaments are the place where phytoplankton grows and lives preferentially. Despite their temporary nature, filaments allow the two phytoplankton species, $P_{1}$ and $P_{2}$, to survive and coexist within them. The frequency of nutrient injections is sufficiently high to prevent the two phytoplankton species from dying between two injections. 

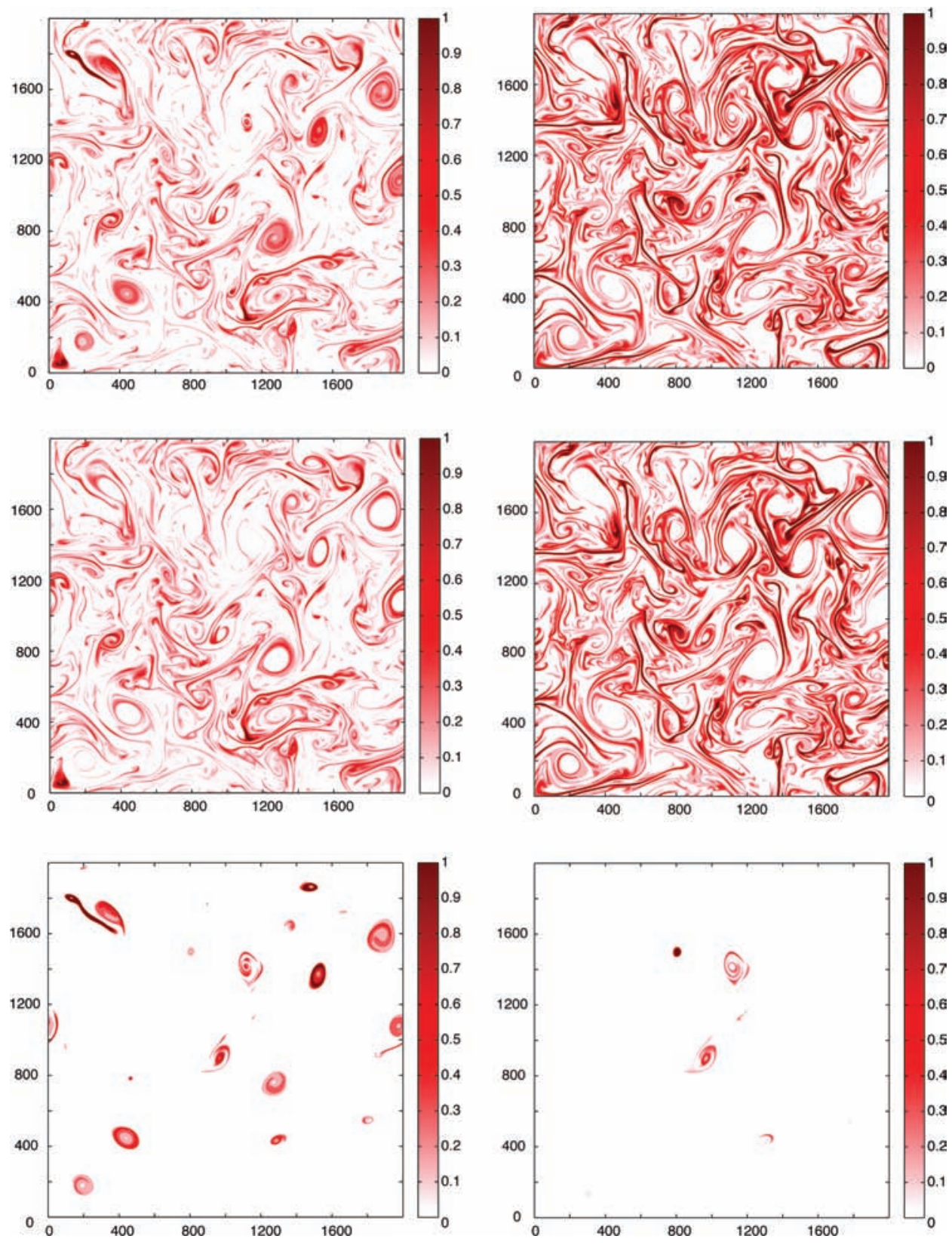

Figure 10. Snapshots at day 786 of $P_{1}$ (left) and $P_{2}$ (right) concentration $\left(\mathrm{mmol} \mathrm{N} \mathrm{m}^{-3}\right.$ ); (top row) reference simulation; (middle row) cut-off of nutrient vertical injections within eddies; (bottom row) cut-off of nutrient vertical injections outside eddies. Axes are in $\mathrm{km}$. 


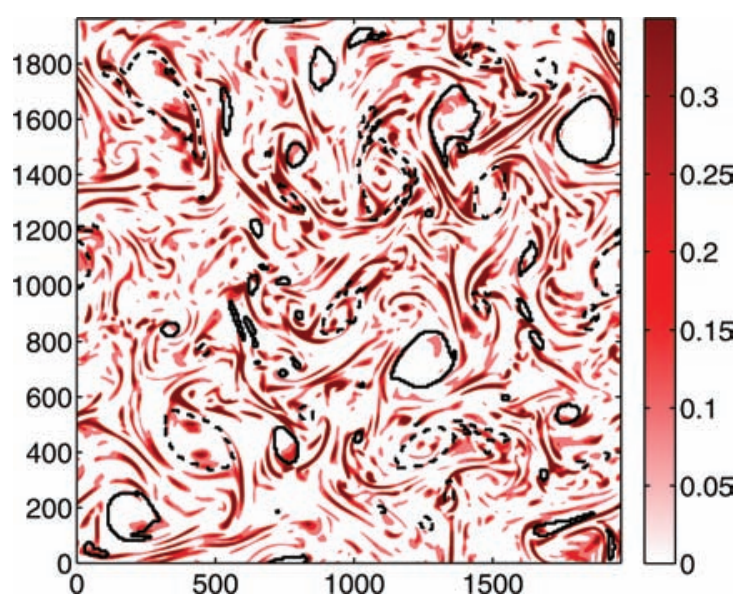

Figure 11. Snapshot at day 786 of nutrient vertical injections in the reference simulation, $-\frac{w^{+}}{h}(N-$ $N_{D L}$ ) in mmol $\mathrm{N} \mathrm{m}^{-3}$ day $^{-1}$. Superimposed are the contours of eddies (continuous contours for warm eddies, dash contours for cold eddies) as diagnosed by the partition algorithm. Axes are in $\mathrm{km}$.

To quantify the role of vertical advection compared with the horizontal one in the reference simulation, we diagnose the horizontal flux $(-\mathbf{u} . \nabla N)$, vertical flux $\left(-w^{+}\left(N-N_{D L}\right) / h\right)$ of nutrients and also biological sources/sinks (three first terms of r.h.s. of Eq. 9) by surface integrating these quantities over individual eddies. By following off-line eddies, we can monitor the time evolution of these eddy-area fluxes of tracers. A temperature criterion is again used to define eddy cores (isoline $1.5^{\circ} \mathrm{C}$ ) and the fluxes are integrated over them. Figure 12 illustrates the results for one of them, representative of the others. This analysis confirms that the magnitude of vertical injections is of one order larger than that of horizontal ones (Fig. 12a). Biological uptakes of nutrients are nearly balanced by vertical injections. Figure $12 \mathrm{a}$ and $\mathrm{b}$ show that peaks of vertical injections are instantaneously correlated with peaks of $P_{1}$ net growth $\left(d P_{1} / d t\right)$ and followed by peaks of $P_{1}$ concentration (delay between the two peaks is close to 5 days). In addition, the $P_{2}$ versus $P_{1}$ growth rate ratio, $\gamma=\frac{\alpha_{2} N /\left(K_{N 2}+N\right)}{\alpha_{1} N /\left(K_{N 1}+N\right)}$ (Eqs. 10 and 11), indicates that $P_{1}$ is all the time more efficient in the eddy core (always $<1)$. The peaks of vertical injections are actually correlated with turbulent interactions between eddies or between an eddy and a filament. The followed eddy undergoes a size variation of about $10 \%$ during the turbulent interactions (not shown).

Observing that eddy-eddy or eddy-filament interactions contribute to $P_{1}$ survival in eddy cores at statistical equilibrium, we describe here the effect of these transient processes on phytoplankton distribution. Figure 13 shows the two phytoplankton species distributions $\left(P_{1}\right.$ on the left and $P_{2}$ on the right) corresponding to the three types of interactions of Figure 6. The top panel represents an isolated eddy which interacts with filaments surrounding it. This induces quite strong vertical injections in the eddy core and the development of $P_{1}$. On the other hand, $P_{2}$ is almost excluded from this eddy. The filamentation of the eddy in a 

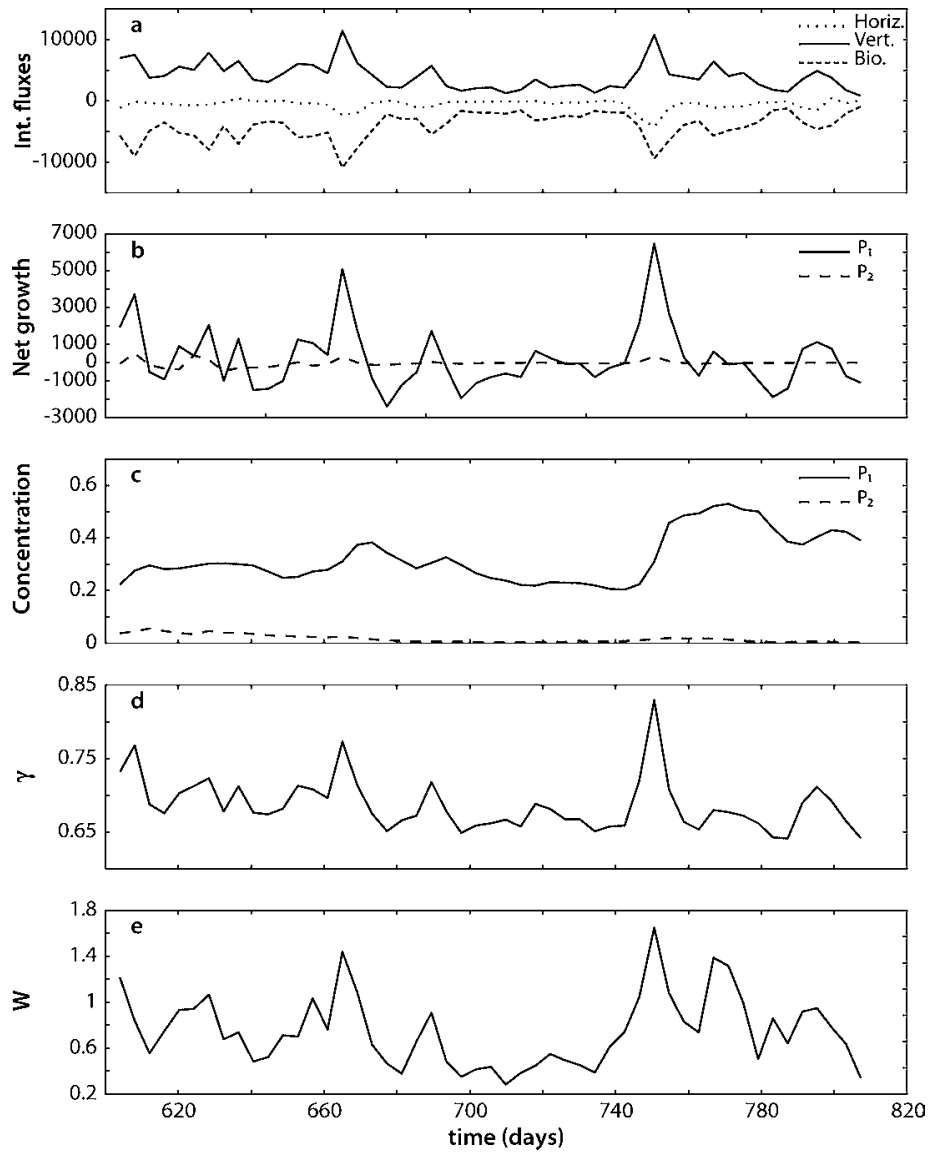

Figure 12. (a) Fluxes integrated over eddy area $\left(\mathrm{mmol} \mathrm{N} \mathrm{m}^{-1} \mathrm{~s}^{-1}\right)$ along the trajectory of one eddy: horizontal flux of nutrients (dotted line); biological flux (dashed line); vertical flux of nutrients (solid line); (b) Integrated net growth of phytoplankton $\left(\mathrm{mmol} \mathrm{N} \mathrm{m}^{-1} \mathrm{~s}^{-1}\right)$ along the eddy trajectory: $P_{1}$ (solid line); $P_{2}$ (dashed line); (c) Integrated concentration $\left(\mathrm{mmol} \mathrm{N} \mathrm{m}^{-1}\right.$ ) along the eddy trajectory: $P_{1}$ (solid line); $P_{2}$ (dashed line); (d) Growth rate ratio $(\gamma)$ along the eddy trajectory; (e) Mean vertical velocity inside the eddy $\left(\mathrm{m}\right.$ day $\left.^{-1}\right)$.

spiral like shape is clearly visible in the $P_{1}$ biomass field as was diagnosed by Lehahn et al. (2007). The middle panel shows the interaction of two like-signed eddies that eventually merge. Merging is the strong interaction via which the stronger eddy 'swallows' all or part of the weaker one. It is characterized by the collapse of the two eddies toward their mid point and by the production of strong small-scale filaments associated with strong vertical velocities as shown on Figure 6 and by Lapeyre and Klein (2006b) in their simulation with three eddies and the merger of two of them (see their Fig. 2). Eddy cores are usually colonized by $P_{1}$, but we observe that a merger can sometimes induce a temporary change 


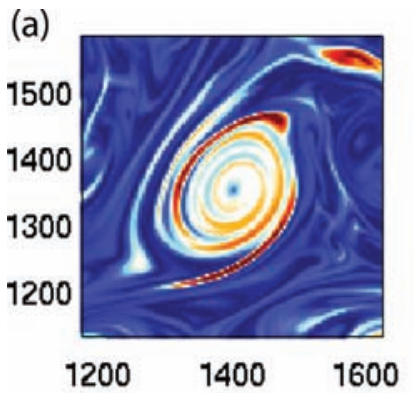

(c)

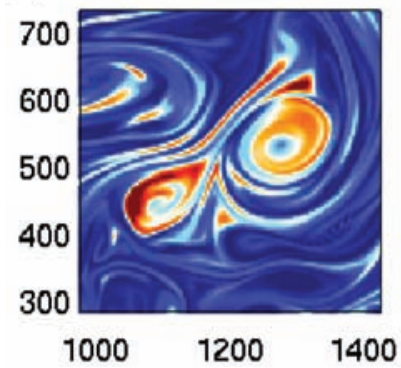

(e)

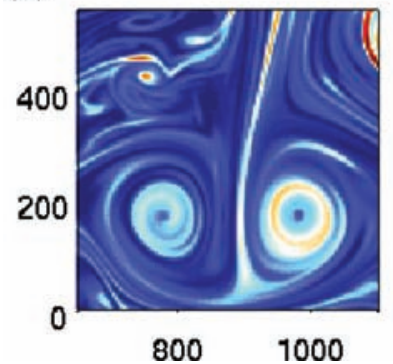

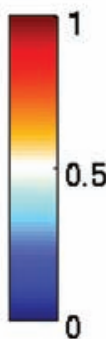
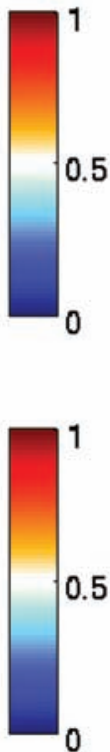

(b)

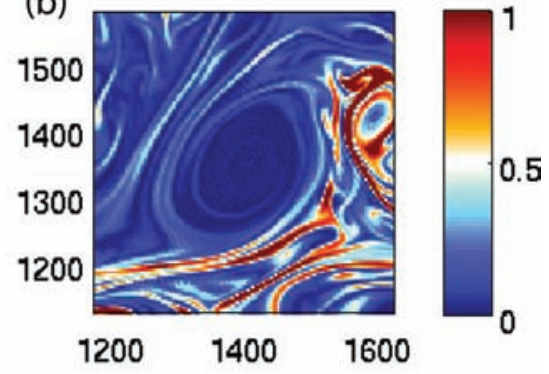

(d)

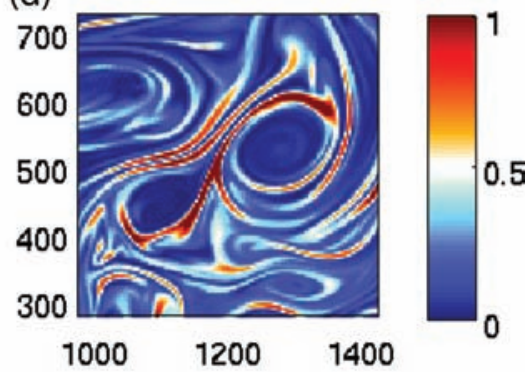

(f)

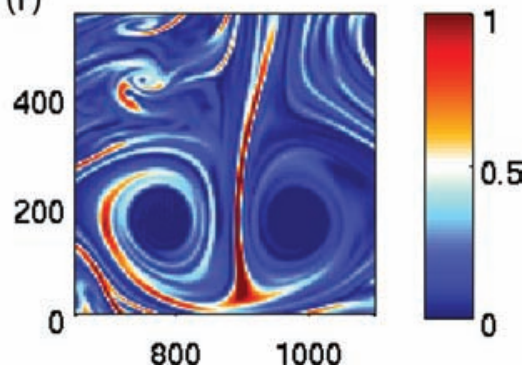

Figure 13. $P_{1}$ (left) and $P_{2}$ (right) concentrations in $\mathrm{mmol} \mathrm{N} \mathrm{m}^{-3}$ corresponding to the three cases of eddy interactions of Figure 6. Axes are in km.

of predominance depending on the size of the absorbed eddy. Here, our two merging eddies induce a colonization of the eddy cores by $P_{1}$ and a strong development of $P_{2}$ at the eddy peripheries. The bottom panel shows a propagating dipole of eddies of opposite sign. During its propagation, the dipole interacts with filaments surrounding it. These interactions form strong filaments between and around the two interacting eddies of the dipole (see Fig. 6). $P_{1}$ grows slightly in the eddies and in filaments curled around them whereas $P_{2}$ grows strongly in filaments. These three types of eddy interactions highlight the diversity of transient interactions that favors either $P_{1}$ or $P_{2}$ and make their coexistence possible for long time scales (preferentially in eddies for $P_{1}$ and in filaments for $P_{2}$ ). They also show the key role of eddy interaction in the development of $P_{1}$ in eddy cores. 
Concerning the distribution of the two phytoplankton species in eddies, as stated before, there is a significant contrast between the periphery and the core of eddies. We know that $P_{2}$ develops through the strong vertical injections in filaments outside eddies. These filaments circle the eddies and thus $P_{2}$ may have the opportunity to colonize eddies. We can assume that these nutrients become rapidly depleted when $P_{2}$ is entrained within the eddy. As the nutrient injections are weaker in eddy cores, $P_{2}$ becomes less competitive. Furthermore, even if the eddies are not completely isolated from the external flow, the residence time within eddies is very long compared with biological time scales (and so is the time to reach the eddy core); therefore $P_{1}$ which develops in eddy core is shielded against the exterior. In this sense, eddies represent ecological niches. This result is consistent with the conclusions of Lehahn et al. (2007) who diagnosed small spots of high chlorophyll in eddy cores, not mixed with the surrounding poorer waters. They attributed them to the 'eddy pumping' (McGillicuddy et al., 1998) or to 2D horizontal cascade. Here, we attribute this $P_{1}$ growth in eddy cores to the nutrient vertical pump inside eddies. The spiral-like shape of eddies prevents $P_{2}$ from being directly confronted to $P_{1}$. Indeed, when $P_{2}$ reaches the eddy core, there does not remain enough nutrients for it to outcompete $P_{1}$.

\section{Conclusions and discussion}

Using an SQG dynamical model coupled with an NPPZD ecosystem model, this study showed that a statistically stationary turbulent flow, characterized by the simultaneous presence of eddies and filaments, can assure a long term coexistence of two phytoplankton species on a single limiting resource, whereas these species would be mutually exclusive in a quiescent ocean. Fine-scale dynamics with consistent nutrient injections are therefore one further possible explanation of the 'paradox of the plankton' (Hutchinson, 1961): they favor phytoplankton diversity in oligotrophic regions where phytoplankton species are strongly limited in nutrients. Depending on the turbulent structures in which they take place, namely eddy or filament, the vertical injections of nutrients favor either one phytoplankton species or the other. In filaments, the large species grows preferentially because of its better competitiveness in high nutrient conditions brought up by strong vertical injections. This dominance of the large species is not exclusive. The two phytoplankton species coexist at statistical steady state in filaments. This is made possible by the transience of filaments in which the ecosystem is constantly perturbed. In eddy cores, the nutrient injections are weaker and the eddies are able to horizontally trap tracers on long time scales. As a result, the small species competitively excludes the large one on long time scales. It was also shown that, during eddy merger, the two phytoplankton species strongly develop, each in its preferential type of dynamical structure (filaments or eddy cores). In this study, we pointed out the key role of filaments in driving coexistence and in being the preferential place for phytoplankton to develop. $64 \%$ of the phytoplankton biomass is actually located in these turbulent structures well outside eddies. 
The coexistence of phytoplankton species submitted to intermittent nutrient injections was already demonstrated by Ebenhöh (1988) in a numerical study in the case of periodical nutrient injections (pulses) in a 0D system. This is in accordance with our conclusion that the intermittency of filaments drives the coexistence. Their results are obtained with a very simplified model with one limiting resource injected by regular pulses, without zooplankton and with phytoplankton species only distinguished by their growth rate, their mortality rate and a threshold of nutrients beyond which they grow. In our SQG simulation, the nutrients are injected on short time scales into filamentary structures in which phytoplankton feels pulses of nutrients.

In our simulation, the initial state is perfectly uniform. Hence, the phytoplankton distribution results only from the mesoscale and submesoscale dynamics which induce vertical injections of nutrients via the mechanism of frontogenesis and at the eddy center. Unlike previous studies, the only source of spatial heterogeneity at the start is the vertical injections of nutrients (within eddies and filaments). Indeed most studies on the impact of fine-scale dynamics on phytoplankton distribution were based on an initial large-scale gradient. Abraham (1998) defined an initial large-scale variability of the carrying capacity (which has the effect of a limiting nutrient). Stirring processes of this initial state resulted in a very finescale phytoplankton field and an even finer zooplankton field. Then, Lévy (2003), using a PE simulation with a large-scale density gradient, showed that positive chlorophyll anomalies in eddies resulted from the 2D cascade of large scale pattern of chlorophyll towards smaller scale. These eddies stemed from the productive side of the front and spread to the other side. Lastly, Bracco et al. (2000), with two species spatially segregated initially showed the shielding effect of vortices. Concerning eddies, we showed in addition to these studies that they can also be intrinsically productive due to vertical nutrient injections in their core and to one phytoplankton species adapted to these weak injections. In the real ocean, the history of eddies and the phytoplankton species within them has to be examined to conclude on the origin of biomass within them. Concerning filaments, we showed that $64 \%$ of the biomass was found within elongated ones (far from eddies) due to strong injections of nutrients induced by frontogenesis. This is consistent with the assumption of Klein and Lapeyre (2009) of filaments being key structures to close the primary production balance of the global ocean.

We intentionally chose a simple configuration of our coupled model in order to focus on the effect of filaments and eddies on the distribution of two phytoplankton species and their potential coexistence. This model is not aimed at reliably reproducing the reality but at rationalizing one part of the observed complexity in phytoplankton distribution. Nevertheless, we discuss the key-processes that are omitted in our study. Concerning the physical processes, the first one is the asymmetry between cyclones and anticyclones. In the real ocean, cyclones are more compact and stronger whereas anticyclones are diffuse and weaker. Hakim et al. (2002) rationalized this asymmetry in vortex structure with an SQG+1 model. They showed that the asymmetry in the divergent flow during frontogenesis is the source of vortex structural asymmetry. This asymmetry will definitely have an influence 
on the outcome of phytoplankton competition within eddies. We expect that anticyclones favor the small species which are more reactive to nutrient inputs. This is in accordance with the observations of Vidussi et al. (2001) in the Eastern Mediterranean: cyclones were dominated by nano- and micro-phytoplankton whereas anticyclones were dominated by nano- and pico-phytoplankton. Sweeney et al. (2003) also measured the concentration of different phytoplankton size classes in mesoscale structures but diagnosed that phytoplankton communities differed in these structures according to the type of eddies and to their age. Secondly, we neglected the effect of atmospheric forcing. Vertical velocities may respond to it. As examined by Giordani et al. (2006) in numerical simulation of the POMME campaign and Thomas et al. (2010) using data from a Japan/East Sea campaign, these velocities can be much larger than the ones deduced only from the QG omega equation. Both turbulent terms and frontal ageostrophic submesoscales concur to increase the asymmetry in cyclonic/anticyclonic filaments and eddies. Thirdly, in the present work we have considered a vertically integrated upper ocean. To get closer to the reality, the light gradient in the water column has to be taken into account in addition with the temporal and spatial distribution of mixed layer depth. The light gradient creates 'ecological niches' along the water column which favor specific classes of phytoplankton. Some ocean dynamical processes are able to mix these species, each of them growing at its preferential depth. For example, Perruche et al. (2010) showed that the diffusion process in the mixed layer is responsible for the coexistence of a few phytoplankton species at a given depth. Including the light gradient would also allow to study the influence of the mechanism of eddy pumping (McGillicuddy et al., 1998) on phytoplankton competition. Fourthly, d'Ovidio et al. (2010) showed with satellite data and the method of Lyapunov exponents how patches of dominant phytoplankton species were stretched by the submesoscale structures and how dominant species can be separated by physical fronts created by horizontal stirring. This process requires a spatial heterogeneity of the species at the start of the experiment before being submitted to horizontal stirring. In reality, the distribution of phytoplankton is constrained by a non-linear combination of all these dynamical processes.

Concerning the biological processes, the state of the art of ecosystem modeling shows that none of the current models is presently able to fully reproduce the complexity of biogeochemical interactions within an ecosystem. Because of the limited computational resources, modelers have to choose only one way to refine their model if they want to embed them in physical model and make statistics on the global ocean. For instance, LeQuére et al. (2005) chose to distinguish between a few phytoplankton classes characterized by their PFT (Plankton Functional Type) among thousands in the reality. Moreover, the rare or missing datasets to assess the numerous parameters of the complex models is another obstacle to their use. In this context, we chose in our study an extremely simple ecosystem model. This choice has already been discussed in the model description section. Let us now discuss its applicability. Follows et al. (2007) and Barton et al. (2010) used the same type of model with Michaelis-Menten growth, linear mortality of phytoplankton and zooplankton, Holling type II grazing, linear remineralization but they took 78 phytoplankton species, 
assigned their parameters stochastically and applied it to the global ocean. Although their model is extremely simplified in terms of parameterization and the parameters are chosen arbitrarily, it is able to reproduce the biogeographic regions of Longhurst et al. (1995) distinguished by observations in terms of biomass concentration but also of the type of emergent ecosystems. Follows et al. (2007) show that their modeled biogeographic regions consist of phytoplankton with appropriate physiological features. These biogeographic regions correspond to large scale dynamical structures. The species diversity in their model allows them to study the natural selection of phytoplankton species when submitted to large-scale dynamical processes. In the present work we adopt a similar methodology, using a model with the same degree of simplicity in parametrizations, to study the competition between only two generic species, but at higher spatial resolution (at meso- and submeso-scale). Our results show that submesoscale dynamics favor diversity. Our two species coexist whereas they were mutually exclusive in a quiescent environment. This is consistent with results of Barton et al. (2010) that diagnose a decrease of diversity toward the pole except in strongly turbulent and energetic regions that they call 'hot spot.'

Knowing now which processes drive the phytoplankton coexistence in this simplified configuration with a crude parameterization of biology and physics, a more complete understanding of the effect of submesoscale processes on plankton diversity requires to further investigate the influence of the top-down control in this context. In the present work, we focused on the influence of nutrient limitation on ecosystem structuring. The zooplankton had a mean control on the two phytoplankton species. We know that the ecosystem response to nutrient enrichment strongly depends on the upper trophic levels (Hulot et al., 2000). Two ways in modeling are explored at the moment to study this question of the role of upper trophic levels. The first one consists in modeling precisely the trophic cascades by using continuously structured size class model (Maury et al., 2007a,b; Baird and Suthers, 2007). The second one consists in considering several plankton functional groups (LeQuéré et al., 2005). This second type of model allows us to study the influence of the ecosystem structure with several food chains of different lengths on phytoplankton diversity. It is clear that submesoscale dynamics will strongly affect such ecosystem structuring. This is left to future investigations.

Acknowledgments. This work was funded by the INSU-CNRS CYBER-LEFE Programme through the TWISTED action, and the French Ministry of Research. Simulations were performed on the NEC-SX8 of the Idris Center.

\section{REFERENCES}

Abraham, E. R. 1998. The generation of plankton patchiness by turbulent stirring. Nature, 391, 577580 .

Anderson, T. and A. Mitra. 2010. Dysfunctionality in ecosystem models: An underrated pitfall? Prog. Oceanogr., 84, 66-68.

Baey, J. and X. Carton. 2002. Vortex multipoles in two-layer rotating shallow-water flows. J. Fluid Mech., 460, 151-175. 
Baird, M. and I. Suthers. 2007. A size-resolved pelagic ecosystem model. Ecol. Model., 203, 185-203. Barton, A., S. Dutkiewicz, G. Flierl, J. Bragg and M. Follows. 2010. Patterns of diversity in marine phytoplankton. Science, 327, 1509-1511.

Blumen, W. 1978. Uniform potential vorticity flow: Part I. Theory of wave interactions and twodimensional turbulence. J. Atmos. Sci., 35, 774-783.

Bracco, A., A. Provenzale and I. Scheuring. 2000. Mesoscale vortices and the paradox of the plankton. Proc. Roy. Soc. London (B), 267, 1795-1800.

Busenberg, S., S. Kumar, P. Austin and G. Wake. 1990. The dynamics of a model of a plankton-nutrient interaction. Bull. Math. Biol., 52, 677-696.

Capet, X., P. Klein, B. Hua, G. Lapeyre and J. McWilliams. 2008. Surface kinetic energy transfer in surface quasi-geostrophic flows. J. Fluid Mech., 604, 165-174.

Claustre, H., P. Kerhervé, J.-C. Marty, L. Prieur, C. Videau and J.-H. Hecq. 1994. Phytoplankton dynamics associated with a geostrophic front: Ecological and biogeochemical implications. J. Mar. Res., 52, 711-742.

Denman, K. and M. Pena. 1999. A coupled 1-D biological/physical model of the northeast subarctic Pacific Ocean with iron limitation. Deep-Sea Res. II, 46, 2877-2908.

d'Ovidio, F., S. De Monte, S. Alvain, Y. Dandonneau and M. Lévy. 2010. Fluid dynamical niches of phytoplankton types. Proc. Nat. Acad. Sci., 107, 18366-18370.

Ebenhöh, W. 1988. Coexistence of an unlimited number of algal species in a model system. Theor. Pop. Biol., 34, 130-144.

Fasham, M., H. Ducklow and S. McKelvie. 1990. A nitrogen-based model of plankton dynamics in the oceanic mixed layer. J. Mar. Res., 48, 591-639.

Flierl, G. and C. Davis. 1993. Biological effects of Gulf Stream meandering. J. Mar. Res., 51, 529-560.

Flynn, K. 2003. Modelling multi-nutrient interactions in phytoplankton; balancing simplicity and realism. Prog. Oceanogr., 56, 249-279.

-2010. Ecological modelling in a sea of variable stoichiometry: dysfunctionality and the legacy of Redfield and Monod. Prog. Oceanogr., 84, 52-65.

Follows, M., S. Dutkiewicz, S. Grant and S. Chisholm. 2007. Emergent biogeography of microbial communities in a model ocean. Science, 315, 1843-1846.

Franks, P. 2002. NPZ models of plankton dynamics: their construction, coupling to physics, and application. J. Oceanogr., 58, 379-387.

Giordani, H., L. Prieur and G. Caniaux. 2006. Advanced insights into sources of vertical velocity in the ocean. Ocean Dyn., 56, 513-524.

Hakim, G., C. Snyder and D. Muraki. 2002. A new surface model for cyclone-anticyclone asymmetry. J. Atmos. Sci., 59, 2405-2419.

Hardin, G. 1960. The Competitive Exclusion Principle. Science, 131, 1292-1297.

Held, I., R. Pierrehumbert, S. Garner and K. Swanson. 1995. Surface quasi-geostrophic dynamics. J. Fluid Mech., 282, 1-20.

Hoskins, B. 1982. The mathematical theory of frontogenesis. Ann. Rev. Fluid Mech., 14, 131-151.

Hoskins, B., I. Draghici and H. Davies. 1978. A new look at the $\omega$-equation. Quart. J. R. Met. Soc., 104, 31-38.

Huisman, J., N. N. Pham Thi, D. Karl and B. Sommeijer. 2006. Reduced mixing generates oscillations and chaos in the oceanic deep chlorophyll maximum. Nature, 439, 322-325.

Huisman, J. and F. J. Weissing. 1999. Biodiversity of plankton by species oscillations and chaos. Nature, 402, 407-410.

Hulot, F., G. Lacroix, F. Lescher-Moutoué and M. Loreau. 2000. Functional diversity governs ecosystem response to nutrient enrichment. Nature, 405, 340-344.

Hutchinson, G. 1961. The paradox of the plankton. Amer. Nat., 95, 137-145. 
Isern-Fontanet, J., G. Lapeyre, P. Klein, B. Chapron and M. Hecht. 2008. Three-dimensional reconstruction of oceanic mesoscale currents from surface information. J. Geophys. Res, 113, C09005.

Jeffrey, S. and G. Hallegraeff. 1980. Studies of phytoplankton species and photosynthetic pigments in a warm core eddy of the East Australian Current. I. Summer populations. Mar. Ecol. Prog. Ser., 3, 285-294.

Klein, P., B. Hua, G. Lapeyre, X. Capet, S. Le Gentil and H. Sasaki. 2008. Upper ocean turbulence from high-resolution 3D simulations. J. Phys. Oceanogr., 38, 1748-1763.

Klein, P., J. Isern-Fontanet, G. Lapeyre, G. Roullet, E. Danioux, B. Chapron, S. Le Gentil and H. Sasaki. 2009. Diagnosis of vertical velocities in the upper ocean from high resolution sea surface height. Geophys. Res. Lett., 36, L12603.

Klein, P. and G. Lapeyre. 2009. The oceanic vertical pump induced by mesoscale turbulence. Ann. Rev. Mar. Sci., 1, 361-375.

Lapeyre, G. and P. Klein. 2006a. Dynamics of the upper oceanic layers in terms of surface quasigeostrophy theory. J. Phys. Oceanogr., 36, 165-176.

-2006b. Impact of the small-scale elongated filaments on the oceanic vertical pump. J. Mar. Res., 64, 835-851.

Legal, C., P. Klein, A. Treguier and J. Paillet. 2007. Diagnosis of the vertical motions in a mesoscale stirring region. J. Phys. Oceanogr., 37, 1413-1424.

Lehahn, Y., F. d'Ovidio, M. Lévy and E. Heifetz. 2007. Stirring of the northeast Atlantic spring bloom: A Lagrangian analysis based on multisatellite data. J. Geophys. Res., 112, C08005.

LeQuéré, C., S. Harrison, I. Prentice, E. Buitenhuis, O. Aumont, L. Bopp, H. Claustre, L. Da Cunha, R. Geider, X. Giraud et al.. 2005. Ecosystem dynamics based on plankton functional types for global ocean biogeochemistry models. Global Change Biol., 11, 2016-2040.

Lesieur, M. and R. Sadourny. 1981. Satellite-sensed turbulent ocean structure. Nature, 673.

LeTraon, P. and R. Morrow. 2001. Ocean currents and eddies. Inter. Geophys. Ser., 69, 171-216.

Lévy, M. 2003. Mesoscale variability of phytoplankton and of new production: Impact of the largescale nutrient distribution. J. Geophys. Res., 108, 3358-3372.

Lévy, M., P. Klein and A.-M. Tréguier. 2001. Impact of sub-mesoscale physics on production and subduction of phytoplankton in an oligotrophic regime. J. Mar. Res., 59, 535-565.

Lima, I., D. Olson and S. Doney. 2002a. Biological response to frontal dynamics and mesoscale variability in oligotrophic environments: Biological production and community structure. J. Geophys. Res., 107, 3111-3131.

2002 b. Intrinsic dynamics and stability properties of size-structured pelagic ecosystem models. J. Plankton Res., 24, 533-556.

Longhurst, A., S. Sathyendranath, T. Platt and C. Caverhill. 1995. An estimate of global primary production in the ocean from satellite radiometer data. J. Plankton Res., 17, 1245-1271.

Martin, A., K. Richards, A. Bracco and A. Provenzale. 2002. Patchy productivity in the open ocean. Global Biogeochem. Cycles, 16, 1025-1033.

Martin, A., K. Richards and M. Fasham. 2001. Phytoplankton production and community structure in an unstable frontal region. J. Mar. Syst., 28, 65-89.

Martin, A. and M. Srokosz. 2002. Plankton distribution spectra: inter-size class variability and the relative slopes for phytoplankton and zooplankton. Geophys. Res. Lett., 29, 2213-2216.

Maury, O., B. Faugeras, Y. Shin, J. Poggiale, T. Ari and F. Marsac. 2007a. Modeling environmental effects on the size-structured energy flow through marine ecosystems. Part 1: The model. Prog. Oceanogr., 74, 479-499.

Maury, O., Y. Shin, B. Faugeras, T. Ben Ari and F. Marsac. 2007b. Modeling environmental effects on the size-structured energy flow through marine ecosystems. Part 2: Simulations. Prog. Oceanogr., $74,500-514$. 
McGillicuddy, D., L. Anderson, S. Doney and M. E. Maltrud. 2003. Eddy-driven sources and sinks of nutrients in the upper ocean: Results from a $0.1^{\circ}$ resolution model of the North Atlantic. Global Biogeochem. Cycles, 17, 1035-1054.

McGillicuddy, D., A. Robinson and J. McCarthy. 1995. Coupled physical and biological modelling of the spring bloom in the North Atlantic (II): three dimensional bloom and post-bloom processes. Deep-Sea Res. I, 42, 1359-1398.

McGillicuddy, D., A. Robinson, D. Siegel, H. Jannasch, R. Johnson, T. Dickey, J. McNeil, A. Michaels and A. Knap. 1998. Influence of mesoscale eddies on new production in the Sargasso Sea. Nature, 394, 263-265.

Mitra, A. and K. Flynn. 2005. Predator-prey interactions: Is 'ecological stoichiometry' sufficient when good food goes bad? J. Plankton Res., 27, 393-399.

2006. Accounting for variation in prey selectivity by zooplankton. Ecol. Model., 199, 82-92.

Mitra, A., K. Flynn and M. Fasham. 2007. Accounting for grazing dynamics in nitrogenphytoplankton-zooplankton models. Limnol. Oceanogr., 52, 649-661.

Olson, D. and R. Hood. 1994. Modelling pelagic biogeography. Prog. Oceanogr., 34, 161-205.

Pasquero, C., A. Bracco and A. Provenzale. 2004. Coherent vortices, Lagrangian particles and the marine ecosystem, in Shallow Flows, G. H. Jirka and W. S. J. Uijttewaal, eds., Balkema Pub., 399-412.

Perruche, C. 2009. Influence de la dynamique mésoéchelle et submésoéchelle sur la compétition au sein d'un écosystème planctonique. Ph.D. thesis. Ecole Doctorale des Sciences de la Mer, 170 pp.

Perruche, C., P. Rivière, P. Pondaven and X. Carton. 2010. Phytoplankton competition and coexistence: intrinsic ecosystem dynamics and impact of vertical mixing. J. Mar. Syst., 81, 99-111.

Rivière, P. and P. Pondaven. 2006. Phytoplankton size classes competitions at sub-mesoscale in a frontal oceanic region. J. Mar. Syst., 60, 345-364.

Roy, S. and J. Chattopadhyay. 2007. Towards a resolution of 'the paradox of the plankton': A brief overview of the proposed mechanisms. Ecological Complexity, 4, 26-33.

Smith, K., G. Boccaletti, C. Henning, I. Marinov, C. Tam, I. Held and G. Vallis. 2002. Turbulent diffusion in the geostrophic inverse cascade. J. Fluid Mech., 469, 13-48.

Sweeney, E., D. McGillicuddy and K. Buesseler. 2003. Biogeochemical impacts due to mesoscale eddy activity in the Sargasso Sea as measured in the Bermuda Atlantic Time-Series Study (BATS). Deep-Sea Res. II, 50, 3017-3039.

Thomas., L., C. Lee and Y. Yoshikawa. 2010. The subpolar front of the Japan/East Sea. Part II: Inverse method for determining the frontal vertical circulation. J. Phys. Oceanogr., 40, 3-25.

Vaillancourt, R., J. Marra, M. Seki, M. Parsons and R. Bidigare. 2003. Impact of a cyclonic eddy on phytoplankton community structure and photosynthetic competency in the subtropical North Pacific Ocean. Deep-Sea Res. I, 50, 829-847.

Vidussi, F., H. Claustre, B. Manca, A. Luchetta and J.-C. Marty. 2001. Phytoplankton pigment distribution in relation to upper thermocline circulation in the eastern Mediterranean Sea during winter. J. Geophys. Res., 106, 939-956.

Williams, R. G. and M. J. Follows. 2003. Physical transport of nutrients and the maintenance of biological production, in Ocean Biogeochemistry: The Role of the Ocean Carbon Cycle in Global Change, M. Fasham, ed., Global Change - The IGBP Series, 19-51.

Received: 27 July, 2009; revised: 24 July, 2011. 